\title{
A method for simultaneous velocity and density inversion and its application to exploration of subsurface structure beneath Izu-Oshima volcano, Japan
}

\author{
Shin’ya Onizawa ${ }^{1}$, Hitoshi Mikada ${ }^{2}$, Hidefumi Watanabe $^{3}$, and Shikou Sakashita ${ }^{3}$ \\ ${ }^{1}$ Institute of Seismology and Volcanology, Graduate School of Science, Hokkaido University, 060-0810, Japan \\ ${ }^{2}$ Deep Sea Research Department, Japan Marine Science and Technology Center, 237-0061, Japan \\ ${ }^{3}$ Earthquake Research Institute, University of Tokyo, 113-0032, Japan
}

(Received June 26, 2001; Revised July 22, 2002; Accepted July 22, 2002)

\begin{abstract}
We have developed a method for three-dimensional simultaneous velocity and density inversion using traveltimes of local earthquakes and gravity data. The purpose of this method is to constrain the velocity inversion and increase the spatial resolution of shallow velocity structures by introducing additional gravity data. The gravity data contributes to the P- and S-wave velocity models by imposing constraints between seismic velocities and density. The constraint curve is constructed so as to fit the data for porous rock samples, and deviations from the curve are taken into account in the inversion. The constraint is imposed at only the first layer, because density structure is well resolved at shallower parts and it is difficult to determine uniquely at greater depths. Synthetic inversion tests indicate that gravity data can improve the resolution of the velocity models for this layer. The method is applied to investigate the subsurface structure of Izu-Oshima volcano, Japan and velocity structures with high spatial resolution are obtained. The additional gravity data contribute primarily to improvement of the $\mathrm{S}$-wave velocity model. At $0.25 \mathrm{~km}$ depth, a high velocity anomaly due to caldera-filling lava flows is observed. At 1.25 and $2.5 \mathrm{~km}$ depths, high velocity intrusive bodies are detected. A NW-SE trending high velocity belt at $1.25 \mathrm{~km}$ depth is interpreted as being caused by repeated intrusion of dikes.
\end{abstract}

\section{Introduction}

In order to understand volcanic activity, it is important to derive the subsurface structure. Inversion for threedimensional velocity structure has been widely used to investigate subsurface structure beneath volcanoes. At shallow depths, however, it is difficult to constrain the structure beneath stations with high spatial resolution, though larger heterogeneity is anticipated. This is due to lack of intersection among seismic rays, since the rays concentrate beneath seismic stations with a dominantly vertical orientation. This problem is more pronounced when seismic stations are sparsely deployed. In general, gravity observations can be carried out more densely than seismic observations. Thus, at shallow depths, the density structure can be obtained at a higher resolution than the velocity structure. This implies that the velocity inversion can be constrained and spatial resolution of the velocity structure can be increased by appropriate use of additional gravity data.

A velocity inversion constrained by gravity data was performed by Lees and VanDecar (1991). They assumed the linear relationship between P-wave velocity and density proposed by Birch (1961) at blocks in a target region, and strictly fixed this relationship. Thus, unknown parameters could be represented only by slowness perturbations. However, Birch's relationship is not appropriate for porous rocks commonly found in the shallow parts of volcanoes. Thus, a

Copy right(C) The Society of Geomagnetism and Earth, Planetary and Space Sciences (SGEPSS); The Seismological Society of Japan; The Volcanological Society of Japan; The Geodetic Society of Japan; The Japanese Society for Planetary Sciences. relationship appropriate for shallow porous rocks should be introduced. Furthermore, it is preferable that the relationship between velocity and density not be fixed, to allow for deviations that better model the real earth.

Izu-Oshima is one of the most active volcanoes in Japan and the latest eruptive event occurred in 1986-1987. Because of its high activity, many geological and geophysical studies have been conducted. The velocity structure has been investigated by previous research, some studies directed toward investigating shallow crustal structure, and some directed toward detecting magmatic bodies (e.g., Hasegawa et al., 1987; Yamamoto, 1993; Mikada, 1994). A consistent result from these studies is that a high velocity zone exists beneath the caldera to a depth of about $2 \mathrm{~km}$ below sea level. However, other results are not necessarily consistent with each other, and we have therefore been unable to derive a complete description of the magma plumbing system.

There are two purposes to this study. One is to develop a method for three-dimensional simultaneous velocity and density inversion combining traveltime data of local earthquakes and gravity data. In this method, gravity data are used to constrain P- and S-wave velocities at the first layer by imposing constraints between $\mathrm{P}$-wave velocity and density and between S-wave velocity and density. The constraints between velocities and density are allowed to vary. Thus, Pand S-wave velocities and density are all unknown parameters. An empirical curve, determined so as to fit data of sedimentary rock samples (Nafe and Drake, 1963), is used to relate velocities to density for porous materials. The sec- 
(a)

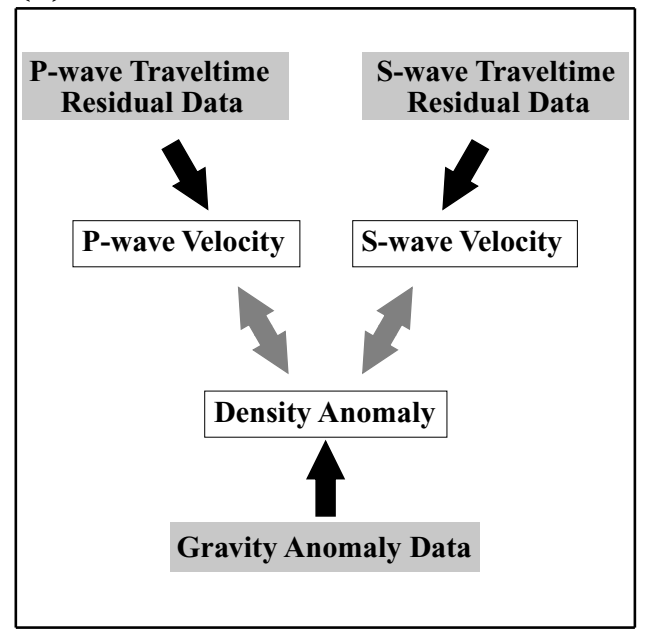

(b)

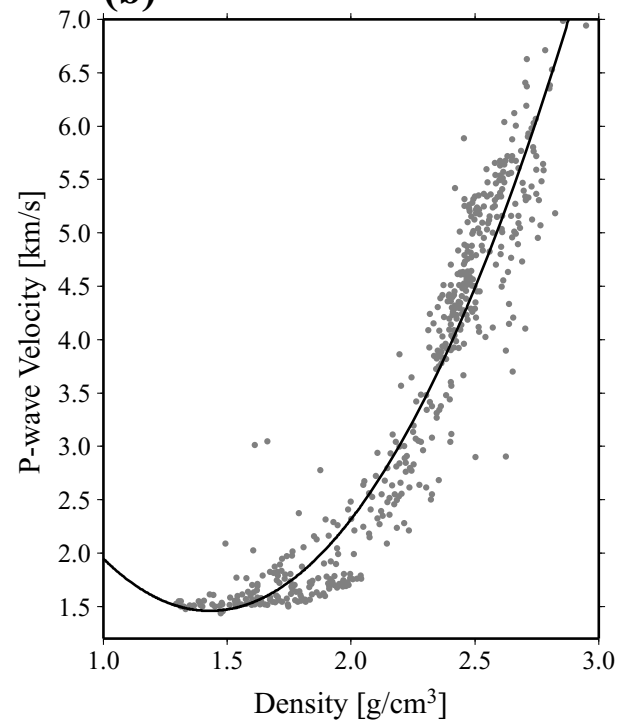

Fig. 1. (a) Basic idea of simultaneous velocity and density inversion. Heavy arrows indicate relationships between data and unknown parameters. Gray arrows show constraints between unknown parameters. In actual analysis, hypocenter locations and origin times are also determined using P- and S-wave traveltime data. In this figure, these are omitted in order to emphasize the relationships between both P- and S-wave velocities and density. (b) The relationship between P-wave velocity and density from laboratory measurements on sediments and sedimentary rocks summarized by Nafe and Drake (1963). The solid curve is the constraint between P-wave velocity and density used in the inversion.

ond purpose is to investigate the subsurface structure beneath Izu-Oshima volcano at a higher spatial resolution than was possible in previous studies. In order to obtain a high spatial resolution, we adopt the following two approaches: 1) application of a simultaneous velocity and density inversion and 2) use of traveltime data from a denser seismic network than was available to previous studies. The number of seismic stations has been increased at Izu-Oshima volcano since the latest eruption in order to better monitor the volcanic activity and to investigate subsurface structures. Currently, a seismic network composed of over 40 stations is operating and seismic records have been accumulated (Sakashita et al., 1996). Densely spaced gravity measurements have also been made on the island (Ando et al., 1994).

In this paper we formulate a simultaneous velocity and density inversion using traveltime and gravity data. We then apply the method to investigate the subsurface velocity structure of Izu-Oshima volcano. Finally, we discuss the implications of the method and the resulting subsurface structure beneath Izu-Oshima volcano.

\section{Method}

The simultaneous velocity and density inversion developed in this paper obtains not only $\mathrm{P}$ - and S-wave velocity models, but also a density model by using gravity data as well as P- and S-wave traveltime data. In our inversion method the gravity data affect $\mathrm{P}$ - and $\mathrm{S}$-wave velocities by imposing constraints between both $\mathrm{P}$ - and $\mathrm{S}$-wave velocities and density, as shown in Fig. 1(a). The constraints between these parameters are not fixed because the relationships must have some variability. Thus, these are all unknown parameters.

In this study, the density structure is obtained only for the first layer because, whereas the shallower part can be well re- solved by gravity data, it is difficult to determine the density distributions uniquely at greater depths since the distribution of gravity data is restricted to the horizontal ground surface. The constraints for the unknown parameters are also imposed at this layer. Only P- and S-wave velocities are investigated in the deeper part. In the following, the observation equations and constraints required for the inversion are described and a target function is formulated.

\subsection{Observation equation 1}

The first observation equation is that used for the usual velocity inversion. Since traveltime data for local earthquakes are used, hypocenter parameters and velocity parameters must both be treated as unknowns. These parameters are determined simultaneously by

$$
\begin{aligned}
\Delta \tau_{i j}= & \sum_{k=1}^{K} \frac{\partial \tau_{i j}^{c a l}}{\partial v_{k}} \Delta v_{k} \\
& +\sum_{l=1}^{3} \frac{\partial \tau_{i j}^{c a l}}{\partial x_{l}} \Delta x_{l j}+\Delta t_{j}^{\text {org }}+O\left(\Delta^{2}\right),
\end{aligned}
$$

where

$$
\Delta \tau_{i j}=\tau_{i j}^{o b s}-\tau_{i j}^{c a l}
$$

for P- and S-waves. $\tau^{o b s}, \tau^{c a l}$ and $\Delta \tau$ denote the observed traveltime, the calculated traveltime and the traveltime residual, respectively. $\Delta v$ is a velocity perturbation. $\Delta x$ and $\Delta t^{\text {org }}$ are perturbations of hypocenter location and origin time, respectively. The last terms of the right-hand side indicate higher-orders of unknown parameters. A suffix $i$ represents a station number $(i=1, \ldots, I), j$ an event number $(j=1, \ldots, J)$ and $k$ a grid number $(k=1, \ldots, K) . x_{l}$ $(l=1,2,3)$ denotes $x, y$ and $z$ in Cartesian coordinates. 
Partial derivatives for velocity perturbations in Eq. (1) (modified from Thurber (1983)) are described as

$$
\frac{\partial \tau^{c a l}}{\partial v_{k}}=\sum_{m=1}^{M} a_{m k}\left(-\frac{1}{V_{m}^{2}}\right) \delta s_{m},
$$

where $V_{m}$ and $\delta s_{m}(m=1, \ldots, M)$ are a velocity and length of $m$-th discrete ray segment, respectively. $a_{m k}$ denotes a coefficient representing weight according to distance of the $m$-th discrete ray segment from the $k$-th velocity grid. For hypocenter locations (Lee and Stewart, 1981),

$$
\frac{\partial \tau^{c a l}}{\partial x_{l}}=-\frac{1}{V} \frac{d x_{l}}{d s}
$$

$V$ and $\frac{d x_{l}}{d s}$ are a velocity and $l$-th component of ray direction at a hypocenter, respectively.

\subsection{Observation equation 2}

The gravity anomaly $\Delta g$ at a point $(x, y, z)$ due to density anomalies $\Delta \rho$ in a region $V$ is

$$
\Delta g(x, y, z)=\iiint_{V} G \frac{z^{\prime}-z}{r^{3}} \Delta \rho\left(x^{\prime}, y^{\prime}, z^{\prime}\right) d x^{\prime} d y^{\prime} d z^{\prime}
$$

where $r=\sqrt{\left(x^{\prime}-x\right)^{2}+\left(y^{\prime}-y\right)^{2}+\left(z^{\prime}-z\right)^{2}}$ and $G$ is Newton's gravitational constant. $\left(x^{\prime}, y^{\prime}, z^{\prime}\right)$ is a coordinate of the density anomaly inside the region $V$. Since in the formulation of the observation equation 1 a grid model is adopted for discrete parameterization of the unknown velocity structure, the densities must also be represented at grid points. However, it is difficult to calculate the volume integral in Eq. (2) analytically if the density varies continuously inside the volume. Thus, density at a grid point is represented by summation of interpolated densities of rectangular prisms smaller than the grid interval, since the gravity anomaly associated with a rectangular prism having a constant density anomaly can be calculated analytically (e.g., Nagy, 1966; Talwani, 1973). The gravity anomaly at the $n$-th observed point due to the density anomaly of $p$-th rectangular prism $\Delta \rho_{p}^{\text {prism }}$ is

$$
\Delta g_{n p}=\Delta g_{n p}^{u n i t} \Delta \rho_{p}^{p r i s m}
$$

$\Delta g_{n p}^{\text {unit }}$ indicates the gravity anomaly at the $n$-th observed point due to the $p$-th rectangular prism having unit density anomaly. This is determined by the geometric setting of the observed point and the rectangular prism. The gravity anomaly at an observation point $\Delta g_{n}$ is the superposition of density anomalies included in the region $V$, thus

$$
\Delta g_{n}=\sum_{p=1}^{P} \Delta g_{n p}^{\text {unit }} \Delta \rho_{p}^{\text {prism }}
$$

The density anomaly of the $p$-th rectangular prism is expressed by a linear interpolation of density anomalies at surrounding grids $\Delta \rho_{k}$ by

$$
\Delta \rho_{p}^{p r i s m}=\sum_{k} b_{p k} \Delta \rho_{k},
$$

where $b_{p k}$ is a coefficient determined by distance between the $p$-th prism and the $k$-th grid. The right-hand side includes eight terms relating grids surrounding the $p$-th prism. Hence, the $n$-th gravity anomaly due to density anomalies at the grid points is described as

$$
\Delta g_{n}=\sum_{k=1}^{K} c_{n k} \Delta \rho_{k},
$$

where

$$
c_{n k}=\sum_{p=1}^{P} \Delta g_{n p}^{u n i t} b_{p k}
$$

\subsection{Constraints between unknown parameters}

To perform the simultaneous inversion, constraints between P-wave velocity and density and between S-wave velocity and density are required. Empirical relations between P-wave velocity and density have been proposed based on laboratory measurements of rock samples. Birch (1961) showed, for igneous rocks, the empirical linear equation relating P-wave velocity to density, known as Birch's law. However, this relationship is applicable to dense rocks commonly found in deeper regions. In our inversion a relationship affected by porosity and appropriate for shallow structures is required. Nafe and Drake (1963) plotted P-wave velocities against densities for samples of marine sediments and sedimentary rocks. Gardner et al. (1974) proposed a relationship for rocks from sedimentary basins. Although both studies are for porous rocks, only the former contains samples having density lower than $2 \mathrm{~g} / \mathrm{cm}^{3}$. Since the density at depths shallower than $450 \mathrm{~m}$ below sea level in Izu-Oshima volcano can be lower than $2 \mathrm{~g} / \mathrm{cm}^{3}$ (Watanabe, unpublished data), the former relationship is more suitable. The relationship between P-wave velocity and density was determined by fitting a curve to the data of Nafe and Drake (1963) (see Fig. 1(b)). A polynomial expression

$$
v^{(P)}=a+b \rho+c \rho^{2}
$$

was selected to fit the non-linear trend and to avoid mathematical complexities. $v^{(P)}$ and $\rho$ represent $\mathrm{P}$-wave velocity and density, respectively. Constants $a, b$ and $c$ were determined by least-squares resulting in $a=6.86, b=-7.55$ and $c=2.64$.

S-wave velocity versus density of rock samples is shown by Ludwig et al. (1970). However, the number of samples is too small to determine a curve similar to that for P-wave velocity and density. Instead, the constraint between S-wave velocity and density was made through the predefined Pwave velocity and density constraint and P-wave velocity and S-wave velocity relationship

$$
v^{(P)}=\alpha v^{(S)},
$$

where $v^{(S)}$ is $\mathrm{S}$-wave velocity and $\alpha$ is defined for each depth. For $\alpha$, we used $v^{(P)} / v^{(S)}$ derived from the one-dimensional velocity inversion described later. The relationship between $\mathrm{S}$-wave velocity and density can be represented as

$$
\alpha v^{(S)}=a+b \rho+c \rho^{2} .
$$

Equations (4) and (6) are the constraints, shown by gray arrows in Fig. 1(a), used in the simultaneous inversion. 


\subsection{Target function}

The observation equations and unknown parameter constraints are combined and a target function is derived in vector form. In non-linear inverse problems the following target function has been widely used to obtain unknown parameters:

$$
T(\boldsymbol{m})=\left\|\boldsymbol{D}_{d}(\boldsymbol{d}-\boldsymbol{f}(\boldsymbol{m}))\right\|^{2}+\left\|\boldsymbol{D}_{m}\left(\boldsymbol{m}_{0}-\boldsymbol{m}\right)\right\|^{2},
$$

where $\boldsymbol{d}, \boldsymbol{m}$ and $\boldsymbol{f}(\boldsymbol{m})$ are the data vector, model parameter vector and a non-linear function relating $\boldsymbol{d}$ and $\boldsymbol{m}$, respectively. $\boldsymbol{m}_{0}$ is an initial guess of model parameters. The first term of the right-hand side is made from the observation equations and the second term is to constrain the model parameters from diverging from the initial guess. $\boldsymbol{D}_{d}$ and $\boldsymbol{D}_{m}$ are diagonal matrices expressed as

$$
\boldsymbol{D}_{d}=\left(\begin{array}{ccc}
\sigma_{d_{1}}^{-1} & & 0 \\
& \ddots & \\
0 & & \sigma_{d_{N}}^{-1}
\end{array}\right), \boldsymbol{D}_{m}=\left(\begin{array}{ccc}
\sigma_{m_{1}}^{-1} & & 0 \\
& \ddots & \\
0 & & \sigma_{m_{M}}^{-1}
\end{array}\right),
$$

where $\sigma_{d}$ is the observational error and $\sigma_{m}$ determines the relative weight between first and second terms in Eq. (7) and corresponds to an a priori error estimate of model parameters in the Bayesian approach (Jackson and Matsu'ura, 1985). Linear inverse problems can be regarded as special cases of the former equation and can be expressed as

$$
f(m)=A m,
$$

where $\boldsymbol{A}$ is a coefficient matrix relating $\boldsymbol{d}$ and $\boldsymbol{m}$ linearly.

In the specific case of the velocity inversion using traveltime data of local earthquakes, the target function $T^{v e l}$ can be constructed by replacing data vector $\boldsymbol{d}$ by observed traveltime data $\boldsymbol{\tau}^{o b s}$, model parameter vector $\boldsymbol{m}$ by P- and S-wave velocities $\boldsymbol{v}^{(P)}, \boldsymbol{v}^{(S)}$, hypocenter location $\boldsymbol{x}$ and origin time $\boldsymbol{t}^{\text {org }}$, and the non-linear function $\boldsymbol{f}(\boldsymbol{m})$ by calculated traveltime $\boldsymbol{\tau}^{\text {cal }}\left(\boldsymbol{v}^{(P)}, \boldsymbol{v}^{(S)}, \boldsymbol{x}, \boldsymbol{t}^{\text {org }}\right)$ in Eq. (7) as

$$
\begin{aligned}
& T^{\text {vel }}\left(\boldsymbol{v}^{(P)}, \boldsymbol{v}^{(S)}, \boldsymbol{x}, \boldsymbol{t}^{\text {org }}\right) \\
& \quad=\left\|\boldsymbol{D}_{d}^{\text {time }(P)}\left(\boldsymbol{\tau}^{\text {obs }(P)}-\boldsymbol{\tau}^{\operatorname{cal}(P)}\left(\boldsymbol{v}^{(P)}, \boldsymbol{x}, \boldsymbol{t}^{\text {org }}\right)\right)\right\|^{2} \\
& \quad+\left\|\boldsymbol{D}_{d}^{\text {time }(S)}\left(\boldsymbol{\tau}^{\text {obs }(S)}-\boldsymbol{\tau}^{\operatorname{cal}(S)}\left(\boldsymbol{v}^{(S)}, \boldsymbol{x}, \boldsymbol{t}^{\text {org }}\right)\right)\right\|^{2} \\
& \quad+\left\|\boldsymbol{D}_{m}^{\text {vel }(P)}\left(\boldsymbol{v}_{0}^{(P)}-\boldsymbol{v}^{(P)}\right)\right\|^{2}+\left\|\boldsymbol{D}_{m}^{\text {vel }(S)}\left(\boldsymbol{v}_{0}^{(S)}-\boldsymbol{v}^{(S)}\right)\right\|^{2} \\
& \quad+\left\|\boldsymbol{D}_{m}^{\text {hypo }}\left(\boldsymbol{x}_{0}-\boldsymbol{x}\right)\right\|^{2}+\left\|\boldsymbol{D}_{m}^{\text {org }}\left(\boldsymbol{t}_{0}^{\text {org }}-\boldsymbol{t}^{\text {org }}\right)\right\|^{2}
\end{aligned}
$$

$(P)$ and $(S)$ in superscript mean P- and S-waves, respectively. For the density inversion, we can similarly use $d=$ $\Delta g$ and $\boldsymbol{m}=\Delta \rho=\rho-\rho_{0}$, where $\Delta g, \Delta \rho, \rho$ and $\rho_{0}$ are gravity anomaly data, density anomaly, unknown density and initial density, respectively. Because the relationship between the gravity anomaly data and unknown density anomaly is linear, then,

$$
A m=G\left(\rho-\rho_{0}\right),
$$

where $G$ is the coefficient matrix composed of components representing the gravity anomaly due to the unit density anomaly. The target function is

$$
\begin{aligned}
T^{\text {dens }}(\boldsymbol{\rho})= & \left\|\boldsymbol{D}_{d}^{\text {grav }}\left(\boldsymbol{\Delta} \boldsymbol{g}-\boldsymbol{G}\left(\boldsymbol{\rho}-\boldsymbol{\rho}_{0}\right)\right)\right\|^{2} \\
& +\left\|\boldsymbol{D}_{m}^{\text {dens }}\left(\boldsymbol{\rho}-\boldsymbol{\rho}_{0}\right)\right\|^{2}
\end{aligned}
$$

In the simultaneous velocity and density inversion, we must combine Eqs. (8) and (9) by introducing further constraints relating the unknown parameters:

$$
\begin{aligned}
T^{\text {const }}\left(\boldsymbol{v}^{(P)}, \boldsymbol{v}^{(S)}, \boldsymbol{\rho}\right) & =\left\|\boldsymbol{D}_{c}^{v p d} \boldsymbol{c}^{v p d}\left(\boldsymbol{v}^{(P)}, \boldsymbol{\rho}\right)\right\|^{2} \\
& +\left\|\boldsymbol{D}_{c}^{v s d} \boldsymbol{c}^{v s d}\left(\boldsymbol{v}^{(S)}, \boldsymbol{\rho}\right)\right\|^{2},
\end{aligned}
$$

$$
\boldsymbol{D}_{c}=\left(\begin{array}{ccc}
\sigma_{c_{1}}^{-1} & & 0 \\
& \ddots & \\
0 & & \sigma_{c_{M}}^{-1}
\end{array}\right)
$$

where $\sigma_{c}^{-1}$ determine the weight of the constraint term. $c^{v p d}$ and $c^{v s d}$ are constraints expressed by Eqs. (4) and (6), respectively. Finally, the target function $T^{\text {total }}$ is constructed from Eqs. (8), (9) and (10), and the unknown parameters are determined by minimizing the following function:

$$
\begin{aligned}
T^{\text {total }}\left(\boldsymbol{v}^{(P)}, \boldsymbol{v}^{(S)}, \boldsymbol{x}, \boldsymbol{t}^{\text {org }}, \boldsymbol{\rho}\right) & =T^{\text {vel }}\left(\boldsymbol{v}^{(P)}, \boldsymbol{v}^{(S)}, \boldsymbol{x}, \boldsymbol{t}^{\text {org }}\right) \\
& +T^{\text {dens }}(\boldsymbol{\rho}) \\
& +T^{\text {const }}\left(\boldsymbol{v}^{(P)}, \boldsymbol{v}^{(S)}, \boldsymbol{\rho}\right) .
\end{aligned}
$$

Since $\tau^{c a l}, c^{v p d}$ and $c^{v s d}$ are non-linear functions, we must solve the problem iteratively.

\section{Application}

Izu-Oshima is a volcanic island located at about $120 \mathrm{~km}$ SSW of Tokyo (Fig. 2(a)). It is one of the most active volcanoes in Japan, and throughout its history most eruptive materials have been basaltic. Figure 2(b) shows the topography and surface features of the island. A caldera located in the center of the island is about $3 \mathrm{~km}$ in diameter. A central cone, Mt. Mihara, is located on the southern caldera floor. The highest elevation is $764 \mathrm{~m}$ above sea level. The regional stress field around the volcano is inferred as compression in the NW-SE direction and tension in the NE-SW direction from the arrangement of flank volcanoes, fissures and dikes, and from seismic focal mechanisms. The stress field is controlled by the collision of the Philippine Sea plate moving in a NW direction and by the bending of the plate due to subduction at the Sagami trough passing NE of Izu-Oshima volcano (Nakamura et al., 1984). The latest eruption occurred in 1986-1987. In 1986, lava flow and pyroclastic eruptions occurred at Mt. Mihara and two newly opened fissures inside and outside the caldera. The directions of these fissures are consistent with the regional stress field.

Many structural investigations using geophysical methods have been conducted at Izu-Oshima volcano. From a seismic refraction survey, Hasegawa et al. (1987) revealed a two-dimensional velocity structure to a depth of about $2 \mathrm{~km}$ below sea level. They observed high velocity layers underlying surface low velocity layers become shallow from the coast to the summit. Mikada (1994) also detected a high velocity anomaly around this depth beneath the caldera by using three-dimensional velocity inversion of local earthquake traveltime data. Ando et al. (1994) constructed a Bouguer anomaly map of Izu-Oshima volcano and the surrounding sea area. A high gravity anomaly within the caldera rim was found, and was interpreted as due to dense lava flows on the caldera floor. Using data from an aeromagnetic survey, 
(a)

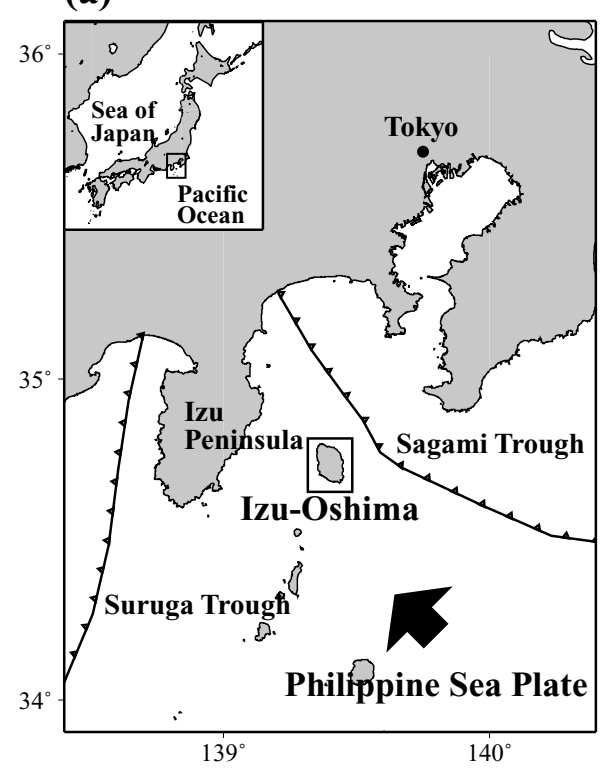

(b)

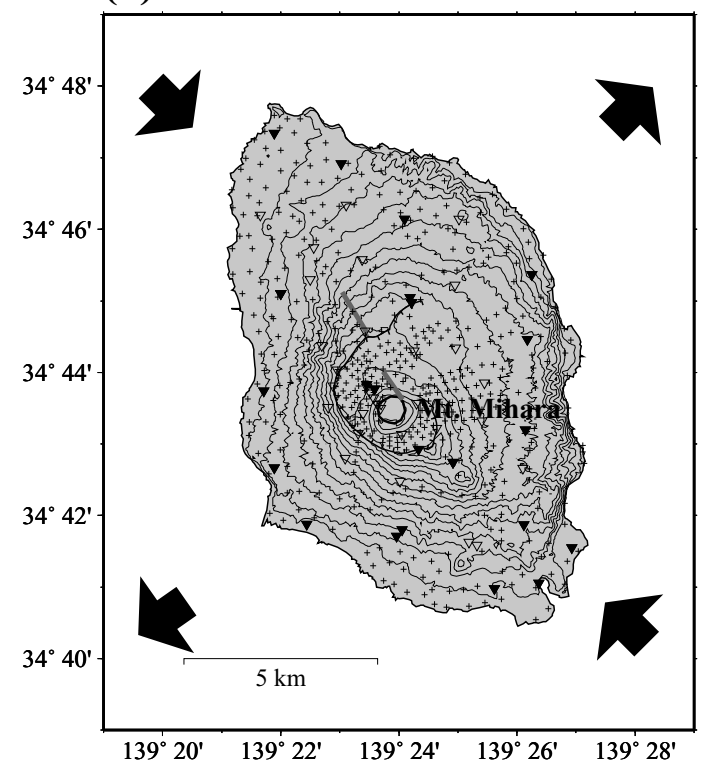

Fig. 2. (a) Index map of Izu-Oshima volcano and surroundings. The arrow indicates the direction of Philippine Sea plate motion. The enclosed area is shown in (b). (b) Topographic map of Izu-Oshima volcano showing surface volcanic features. The topographic contour interval is $50 \mathrm{~m}$. The curve with tick marks indicates the caldera rim. A central cone, Mt. Mihara, rests on the southern caldera floor. Two gray lines inside and outside the caldera show locations of fissure eruption in 1986. Arrows indicate directions of principal axis of the regional stress field (Nakamura et al., 1984). Open inverse triangles: stations equipped with a vertical component seismometer. Solid inverse triangles: stations equipped with a three-component seismometer. The numbers of stations used for the analysis were 56 for P-waves and 24 for S-waves. Crosses: locations of gravity measurement on the island. The number of gravity measurements is 447 .

Makino et al. (1988) detected an intensely magnetized body which crosses the island in a NW-SE direction, and interpreted this body as due to solidified intrusive magma bodies.

\subsection{Data}

3.1.1 Arrival time data Arrival time data of local earthquakes recorded at seismic stations deployed on the volcano by Izu-Oshima Volcano Observatory, University of Tokyo (OVO) and Japan Meteorological Agency (JMA) were used for this study. In April 1986, OVO established a seismic network consisting of seven three-component seismometers to monitor volcanic activity. Since the 1986 eruption, the seismic network has been greatly expanded by OVO not only for monitoring volcanic activity, but also for investigating subsurface structure. Currently, a dense seismic network composed of over 40 permanent stations is in operation (Sakashita et al., 1996).

Events observed during two periods were used in our analysis. These are (a) from April, 1986 through March, 1987 and (b) from August, 1995 through July, 1999. Period (a) includes events that occurred during the 1986 eruption, while period (b) was non-eruptive. In period (b), hypocenters were better constrained, especially beneath the island, because of the dense seismic network. Location errors were estimated as an order of $10 \mathrm{~m}$ and $100-300 \mathrm{~m}$ for events occurred at depths less and greater than $3 \mathrm{~km}$ respectively at a confidence level of one standard deviation. Selected events for this period required that arrival times were available from many stations. However, since earthquakes occurred in restricted regions during the non-eruptive period, seismic rays did not sufficiently illuminate the target region. In period (a) fewer seismic stations were available than in period (b), but hypocenters were distributed across the whole island, especially for the events accompanying the eruption. For period (a), events that occurred in regions where seismicity was low in the non-eruptive period were selected.

The following conditions were imposed on the selection of seismic events. (1) Both P- and S-phases were picked. (2) For the period (a), at least seven phases were available. (3) For the period (b), at least 20 phases were available. (4) The weighted root-mean-square (WRMS) of traveltime residuals was less than $0.2 \mathrm{~s}$ after the initial hypocenter determination. All arrival times were picked from records of $1 \mathrm{~Hz}$ seismometers. S-phases were always picked on horizontal components of seismograms from stations equipped with threecomponent seismometers. The number of events selected for the analysis was 504, and the numbers of stations used for Pand S-waves were 56 and 24 (Fig. 2(b)), respectively. The total numbers of P- and S-wave arrival times were 9675 and 2890 , respectively. All of the arrival times were consistently picked for this study.

3.1.2 Bouguer anomaly data Gravity data have been obtained on the island by Ando et al. (1994) and surrounding sea area by Kato et al. (1987). Using these data, Ando et al. (1994) constructed a Bouguer anomaly map of the Izu-Oshima region by assuming a Bouguer density of 2.27 $\mathrm{g} / \mathrm{cm}^{3}$. The value was inferred from the G-H (gravityheight) method. However, we reconstructed it by adopting the Bouguer density of $1.96 \mathrm{~g} / \mathrm{cm}^{3}$, which was an average of the in situ density profile above sea level obtained from a borehole gravity survey (Watanabe, unpublished data). Locations of gravity measurement on the island are shown in Fig. 2(b). The number of gravity measurements is 447 . 


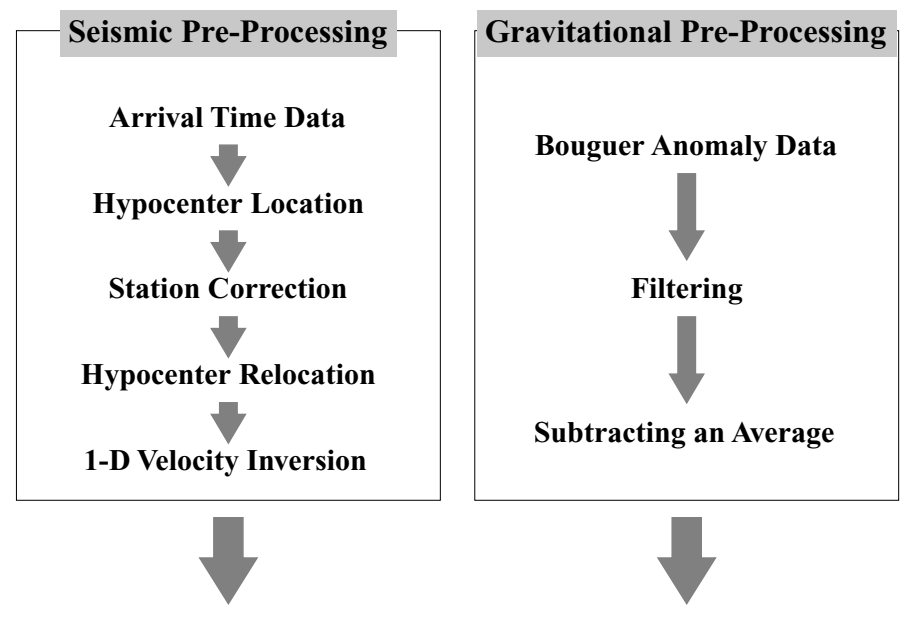

3-D Simultaneous Inversion

Fig. 3. Flowchart of the whole analysis. See text for explanation.

\subsection{Analysis}

In the simultaneous velocity and density inversion, traveltime residuals and gravity anomaly data are used. These data are constructed from arrival time and Bouguer anomaly data through the following pre-processing procedures. A flow chart of these procedures is shown in Fig. 3. Hereafter, all depths are measured from sea level.

3.2.1 Seismic pre-processing The processing of the seismic data involves (1) determining initial hypocenters, (2) determining station corrections, (3) relocating hypocenters and (4) performing a one-dimensional velocity inversion.

First, hypocenters for an initial one-dimensional velocity structures were determined. The one-dimensional velocity structures are shown in Fig. 4(a). Squares and circles indicate the depths of the grids where velocities are defined. Between grids, velocities are given by linear interpolation. A grid at a depth of $-1 \mathrm{~km}$ is set above the surface. The initial P-wave velocity structure to a depth of $2 \mathrm{~km}$ is based on the result of the seismic refraction experiment on Izu-Oshima island (Hasegawa et al., 1987). In the result of Hasegawa et al. (1987), velocities are greater than $5.5 \mathrm{~km} / \mathrm{s}$ at depths greater than $2 \mathrm{~km}$. However, the WRMS of traveltime residuals after the initial hypocenter determinations indicates velocities lower than $5.5 \mathrm{~km} / \mathrm{s}$ are better suited for a depth of $2.5 \mathrm{~km}$. After trial and error calculations, a velocity of $5.2 \mathrm{~km} / \mathrm{s}$ was adopted for this depth. Velocities in regions deeper than 2.5 $\mathrm{km}$ are uncertain. Therefore, a profile of seismic velocity in the Izu-Bonin arc by Suyehiro et al. (1996) was referred to as representative of oceanic arc structure. Initial velocities of S-wave $v_{0}^{(S)}$ were determined from initial P-wave velocities $v_{0}^{(P)}$ through the relationship for a Poissonian solid, i.e., $v_{0}^{(P)} / v_{0}^{(S)}=\sqrt{3}$.

The locations of initial hypocenters are shown in Fig. 4(b). The occurrence of earthquakes is not uniform around IzuOshima volcano. Seismicity in the northwestern part is relatively high and events deeper than $2 \mathrm{~km}$ frequently occur. Depths of events inside and to the east of the caldera are almost all less than $2 \mathrm{~km}$. In the southern part, fewer earthquakes have occurred. Events located in the southeastern part are those of seismic activity after the fissure eruption.

Well-located hypocenters are preferred for the inversion. Although velocity variation exists three-dimensionally, initial hypocenters were determined using the one-dimensional velocity structure. In order to remove the three-dimensional effect in shallower parts, hypocenters were relocated using traveltime residuals with the station dependent corrections subtracted. These corrections were made by averaging the traveltime residuals for each station after the initial hypocenter locations were determined. The corrected traveltime residual data were used only in the hypocenter relocation step. In the steps of subsequent one-dimensional velocity inversion and three-dimensional simultaneous inversion, traveltime residuals without the correction were used again because the station corrections may have included structural information, which we wanted to obtain. Figure 4(c) shows the station corrections. In general, stations with early arrivals are observed in the central part of the volcano for both P- and $\mathrm{S}$-waves. This feature is consistent with the high velocity beneath the caldera revealed by former studies (Hasegawa et al., 1987; Mikada, 1994). Relocated hypocenters are much less scattered (Fig. 4(d)). This implies three-dimensional heterogeneity at shallow depths strongly affects traveltime data observed at seismic stations.

In order to obtain a better initial structure for the threedimensional simultaneous inversion, a one-dimensional velocity inversion was performed by using traveltime residual data after the initial hypocenter determination and the relocated hypocenters. In this step velocities at depths from 0.25 to $6 \mathrm{~km}$ were treated as unknowns. Hypocenter parameters and velocities at the depths of $-1 \mathrm{~km}, 8 \mathrm{~km}$ and deeper where rays were not sufficient were fixed to initial values. No other constraints such as damping were imposed. The result of the one-dimensional inversion is shown in Fig. 4(a).

3.2.2 Gravitational pre-processing In this study, density anomalies are investigated at only the first layer, 0.25 $\mathrm{km}$. The background density at this depth was determined as $2.16 \mathrm{~g} / \mathrm{cm}^{3}$ through the P-wave velocity and density relationship. $\alpha$ of 1.84 for the S-wave velocity and density constraint 
(a)

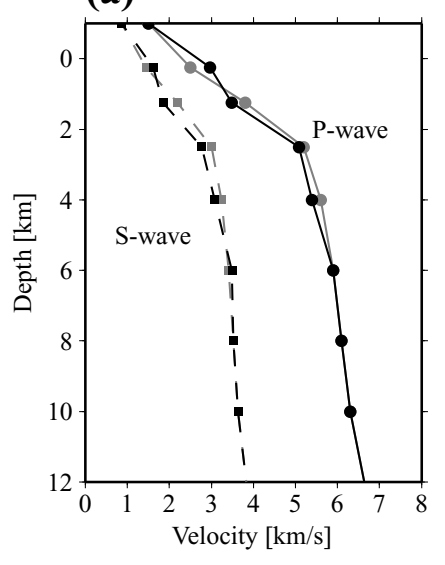

(c)
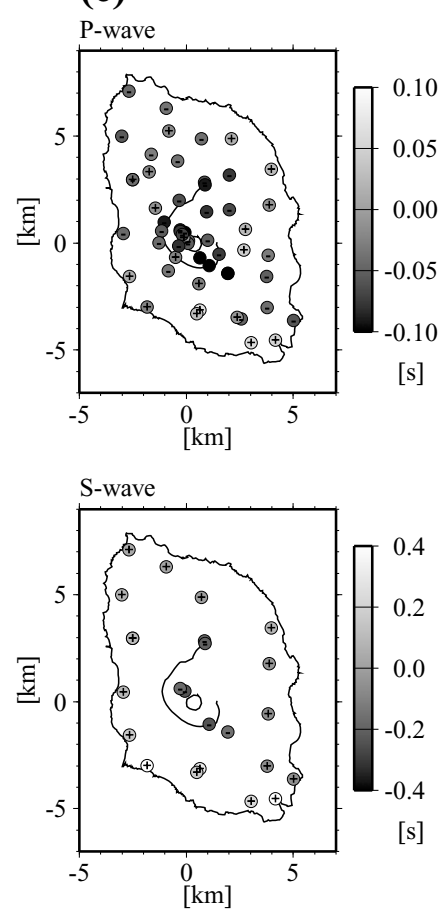

(b)

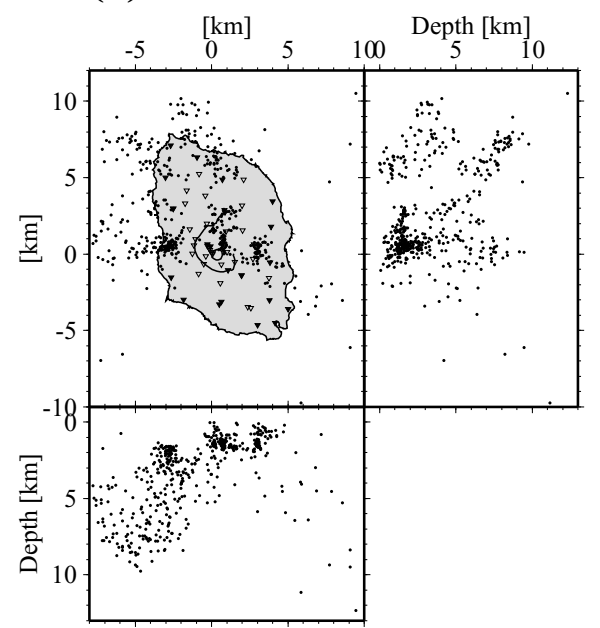

(d)

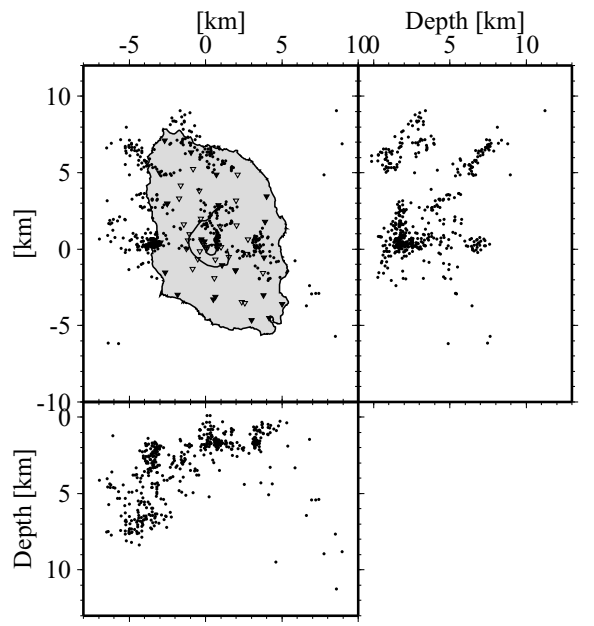

Fig. 4. (a) One-dimensional velocity structure. Solid and broken lines indicate one-dimensional P- and S-wave velocity structures, respectively. Gray lines are the initial structures and heavy lines are the structures after the one-dimensional velocity inversion. Circles and squares show the depths of the grids. (b) Initial hypocentral map. Dots: initial hypocenters. 504 events were used for the analysis. (c) Station corrections for P- and S-waves. Early and delayed arrival stations are shown by darker circles with minus-symbol and lighter circles with plus-symbol, respectively. (d) Hypocenters relocated after the station corrections.

was determined from $v^{(P)} / v^{(S)}$ after the one-dimensional velocity inversion.

The Bouguer anomaly data include the effect due to the density anomaly in a region from the ground surface to an unknown depth. Since in this analysis density anomalies were obtained only at the first layer, wavelengths longer than $4 \mathrm{~km}$ were removed from data resampled in even-space in order to remove the effect due to the density anomalies associated with deeper structures. Wavelengths shorter than $1 \mathrm{~km}$ were also removed because the spatial interval of gravity measurements is approximately $500 \mathrm{~m}$ and components shorter than $1 \mathrm{~km}$ can be regarded as noise. Consequently, velocity structures whose wavelengths longer than $4 \mathrm{~km}$ and shorter than $1 \mathrm{~km}$ tend to be suppressed at the $0.25 \mathrm{~km}$ depth in the resultant model.

The number and distribution of gravity anomaly data are important factors determining contribution to the inversion result. So, after the filtering process was carried out for the even-spaced data, we defined gravity anomaly data at the observation locations again. Since the target region in the simultaneous inversion is only just beneath the island, we used gravity anomaly data only from the island. These procedures made the data biased. The bias was therefore removed by subtracting an average of the gravity anomalies.

The gravity anomaly data used for the simultaneous inversion are shown in Fig. 5. The prominent feature of the gravity anomaly map is that positive anomalies are enclosed by the caldera rim. 


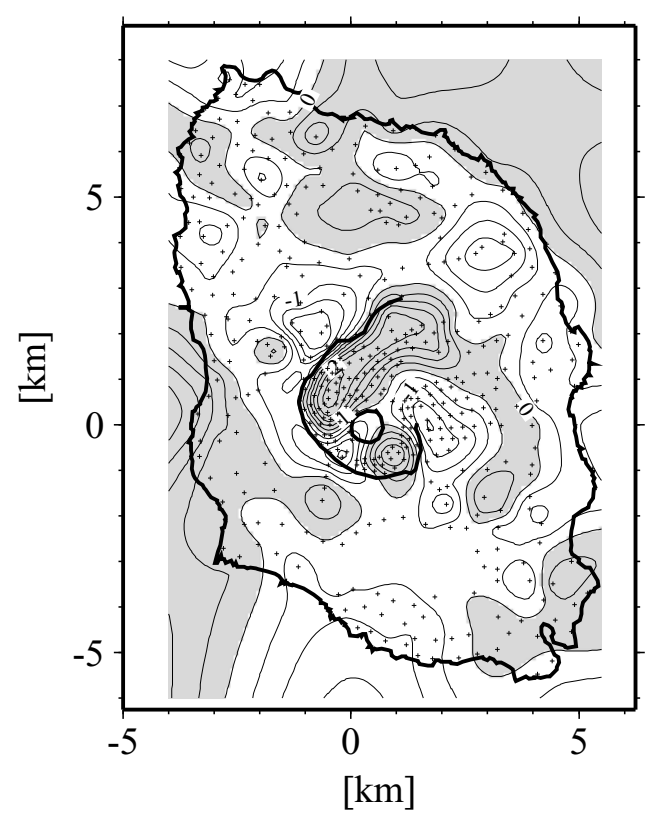

Fig. 5. Observed gravity anomaly data. Contour interval is $0.5 \mathrm{mgal}$ Shaded and white areas correspond to positive and negative anomalies, respectively.

3.2.3 Three-dimensional simultaneous velocity and density inversion After the pre-processing procedures, three-dimensional simultaneous velocity and density inversion was performed. Grid points in the vertical direction are the same as those in the one-dimensional velocity inversion (Fig. 4(a)). In the horizontal direction, in order to make effective use of dense gravity data, we set grids at depths of -1 and $0.25 \mathrm{~km}$ to be finer than those in the deeper region, by modifying a method for uneven grid spacing by Yakiwara and Shimizu (1997). The intervals are $1.25 \mathrm{~km}$ at depths of -1 and $0.25 \mathrm{~km}$, and $2.5 \mathrm{~km}$ at depths of $1.25 \mathrm{~km}$ and deeper. Grids at the depth of $-1 \mathrm{~km}$ are set above the surface. These are for defining velocities from the surface to the depth of $0.25 \mathrm{~km}$. Since rays do not penetrate at the $-1 \mathrm{~km}$ depth, velocities are fixed to an initial value. Thus, velocities in the region shallower than $0.25 \mathrm{~km}$ are reflected in the result for the first layer, $0.25 \mathrm{~km}$ depth. Seismic rays are calculated by taking into account the elevation of a seismic station. The pseudo-bending method of Um and Thurber (1987) was used to trace seismic rays in the three-dimensional inhomogeneous medium. The local topography may affect the calculation of ray paths. We think, however, that the effect is not severe at Izu-Oshima volcano because the topographic variation on the island is from sea level to $764 \mathrm{~m}$ at the summit and this range is smaller than the grid interval of the inversion. Thus, the topography between seismic stations is not considered. For the matrix calculation, the conjugate gradient method (e.g., Scales, 1987) was used. The advantages of this method are that it requires less memory and has a quicker computation time, and the method is suitable for a large sparse matrix calculation.

In the simultaneous inversion, parameters which determine the relative weight of each term in the target function (Eq. (11)) must be given. These are errors of data $\sigma_{d} \mathrm{~s}$ for $\mathrm{P}-$ and S-wave traveltime residuals and gravity anomalies, parameters for terms to suppress divergence of unknowns $\sigma_{m} \mathrm{~s}$ for P-and S-wave velocities, hypocenter location, origin time and density, and parameters for the constraint term $\sigma_{c} \mathrm{~s}$ between P-wave velocity and density and between S-wave velocity and density. Since the results of the inversion depend on these parameters, it is important to choose appropriate values. To examine the dependencies of the inversion results on these parameters, we performed inversions using various combinations of values of parameters and compared the results. In general, these parameters affect each other. However, since the number of parameters is large in the simultaneous inversion and it is difficult to examine all possible combinations of these parameters, we performed test inversions by fixing the parameters, except for the target parameter, as follows.

For $\sigma_{d} \mathrm{~S}$ of $\mathrm{P}$ - and S-wave traveltime residual data, the picking errors of each arrival time were used. It is difficult to determine the error of each gravity anomaly data individually. Therefore, based on a description by Ando et al. (1994) for errors of gravity measurements and elevation determinations, we adopted $0.1 \mathrm{mgal}$ for error of all gravity anomaly data.

Then, we considered $\sigma_{m} \mathrm{~s}$. In general, as $\sigma_{m} \mathrm{~s}$ are set larger, the data residuals are reduced, but unknown parameters tend to become divergent and may have unacceptable values. In contrast, smaller $\sigma_{m}$ s lead to smaller unknown perturbations and smaller data residual reductions. Therefore, we must choose values which sufficiently reduce the data residuals and do not allow the unknowns to become divergent. According to the result of the refraction survey (Hasegawa et al., 1987), P-wave velocities vary about $2 \mathrm{~km} / \mathrm{s}$ at same depths. Thus we guess P-wave velocities can deviate about $1 \mathrm{~km} / \mathrm{s}$ from the reference one-dimensional structure. In order to choose $\sigma_{m} \mathrm{~s}$ for P-wave and S-wave velocities and density, we constructed trade-off curves of the WRMS of data versus $\sigma_{m}$ (Figs. 6(a)-(c)) and of the L2-norm of model parameter perturbations from the initial value $\left\|\boldsymbol{m}_{0}-\boldsymbol{m}\right\|^{2}$ versus $\sigma_{m}$ (Figs. 6(d)-(f)). In this step, all unknowns except for a target parameter were fixed to initial values, and only the target parameter was dealt with as unknown. Constraints between unknown parameters were also not considered. For example, to make trade-off curves for P-wave velocity, we performed the velocity inversions for which the only unknown was the P-wave velocity and for which the S-wave velocity and hypocenter parameters were fixed. For the density anomaly, the test was performed by density inversions. It is difficult to determine the parameter $\sigma_{m}$ uniquely from the trade-off curves. We, therefore, tried several combinations of $\sigma_{m}$ s for the final inversion. Although all results are not shown, basically similar results were obtained. The values of parameter $\sigma_{m}$ s selected for the simultaneous inversion of which we show the results later were $0.1 \mathrm{~km} / \mathrm{s}, 0.05$ $\mathrm{km} / \mathrm{s}$ and $0.05 \mathrm{~g} / \mathrm{cm}^{3}$ for P-wave, S-wave velocities and density, respectively (solid squares in Fig. 6). Then, $\sigma_{m} \mathrm{~s}$ for the hypocenter locations and origin times were examined by using the velocity inversion in which velocities and hypocenter parameters were unknowns. In this inversion, $\sigma_{m} \mathrm{~s}$ for velocities adopted in the former step were used, and $0.05 \mathrm{~km}$ and $0.02 \mathrm{~s}$ were derived.

In the next step, $\sigma_{c} \mathrm{~s}$ were determined. These parame- 
P-wave Velocity

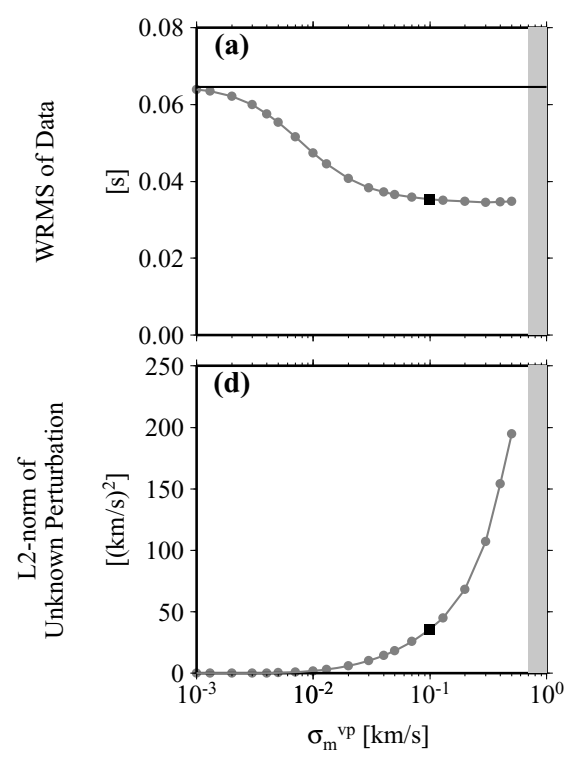

S-wave Velocity
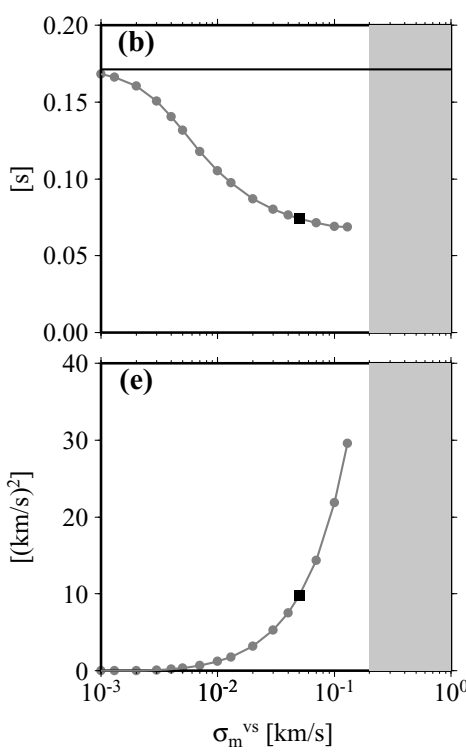

Density
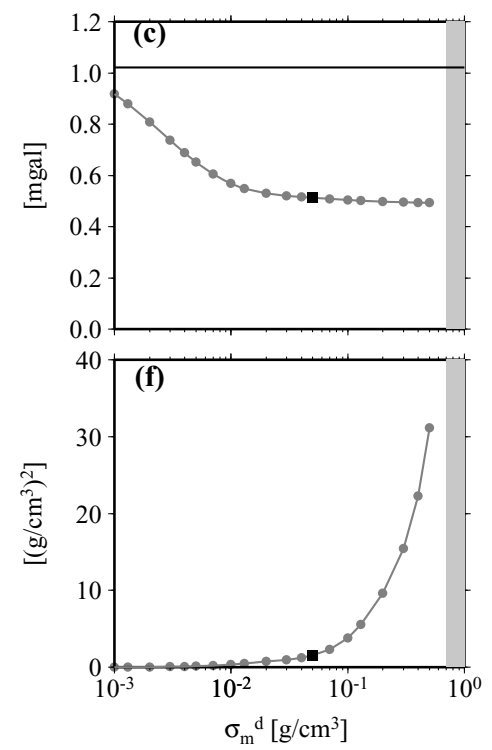

Fig. 6. Trade-off curves for selecting the parameter $\sigma_{m} \mathrm{~s}$. Solid squares indicate parameters selected for the inversion. Use of parameter $\sigma_{m} \mathrm{~s}$ within ranges shown by hatched area leads to divergent results so large that the unknown parameters have negative value, which is physically impossible. (a)-(c): WRMS of data residuals versus $\sigma_{m}$. Solid horizontal lines indicate initial values of WRMS before the inversion. (d)-(f): L2-norm of model parameter perturbations from the initial value $\left\|\boldsymbol{m}_{0}-\boldsymbol{m}\right\|^{2}$ versus $\sigma_{m}$.

ters govern how the gravity data affect the velocity models. Smaller $\sigma_{c} \mathrm{~s}$ result in velocities and density for each grid after the inversion strongly fitting the constraint curves (Figs. 7(a) and (f)), though WRMS reductions become smaller (Figs. 7(d), (e), (i) and (j)). As $\sigma_{c}$ s increase, velocities and density deviate from the constraint curves. Extremely large $\sigma_{c}$ s lead to results similar to those of the velocity inversion and density inversion performed independently (Figs. 7(b) and (g) for the constraint and (d), (e), (i) and (j) for the WRMS). Our criteria for selecting appropriate values were based on 1) the deviation of the samples by Nafe and Drake (1963) and 2) the WRMS of traveltime residual and gravity anomaly data. We adopted $\sigma_{c} \mathrm{~s}$ whose deviations from the relationship after the simultaneous inversion were similar to the deviations of the samples. For the P-wave velocity and density constraint, we performed simultaneous inversions where only P-wave velocity and density were unknowns. The values of $\sigma_{m}$ s determined in the previous step were used for these unknowns. As for the S-wave velocity and density relationship, the same procedure was performed by multiplying $\alpha$, determined by the one-dimensional velocity inversion, with the $\mathrm{S}$-wave velocity. Finally, $0.07 \mathrm{~km} / \mathrm{s}$ was adopted for $\sigma_{c} \mathrm{~s}$ of both the P-wave velocity-density and S-wave velocity - density relationships (Figs. 7(c) and (h)). For the value of $\sigma_{c} \mathrm{~s}$, the WRMS became as small as those of the non-constrained case (Figs. 7(d), (e), (i) and (j)). Thus, we think the inversion result for these parameters satisfies both the data and the constraints.

Checkerboard tests were performed to estimate the resolution of the obtained structures. $\pm 0.5 \mathrm{~km} / \mathrm{s}$ anomalies were added to the reference one-dimensional velocity model for Pwaves as a synthetic velocity structure. The synthetic $S$-wave velocity structure was constructed from the synthetic P-wave velocity through $v^{(P)} / v^{(S)}$ for each grid depth determined by the one-dimensional velocity inversion. The synthetic density anomaly structure was constructed from the P-wave velocity - density relationship and by subtracting the background density from the synthetic density. Synthetic traveltime residual and gravity anomaly data were constructed for these structures. In order to represent the observational error, Gaussian noise was added according to the errors of the original data. Using the synthetic data, the simultaneous inversion was performed to assess its ability to reconstruct the checkerboard velocity anomalies.

\subsection{Results}

The simultaneous inversion was performed using the parameters determined previously, and stably converged after five iterations. Table 1 shows comparisons of values of the target functions and WRMS of data residuals before and after the inversion. Reduction of the target function after the inversion, compared to the initial value, was $72 \%$. As for the WRMS of P- and S-wave traveltime data residuals and gravity anomaly residuals, these were $52 \%, 60 \%$ and $46 \%$, respectively.

In Fig. 8, the P-wave velocity structure is shown with the distribution of total ray length used to determine the velocity for each grid and the result of the corresponding checkerboard test. As expected from hypocenter locations (Fig. 4(d)), at the depths of 2.5 and $4 \mathrm{~km}$, the northwestern quadrant is better illuminated by seismic rays, while the eastern and southern parts are less illuminated (Figs. 8(g) and (h)). The checkerboard test indicates that the velocity structure is well resolved at depths from 0.25 to $2.5 \mathrm{~km}$ (Figs. 8(i)-(1)). The regions where more than $30 \%$ of the synthetic checkerboard anomaly was reconstructed are shown in Figs. 8(a)-(d). At a depth of $0.25 \mathrm{~km}$, a high velocity region enclosed by the caldera rim is observed. The region is fairly well correlated with the topography. At a depth of 


\section{P-wave Velocity - Density}

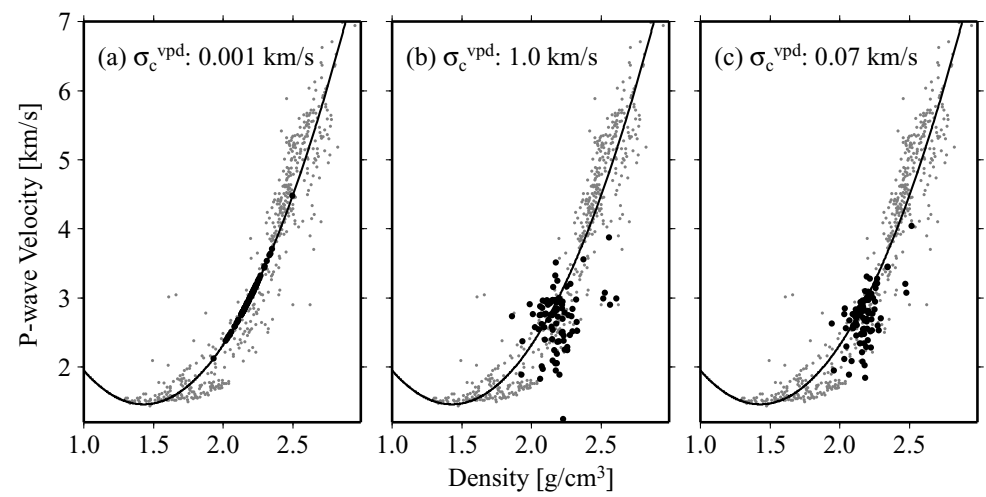

S-wave Velocity - Density

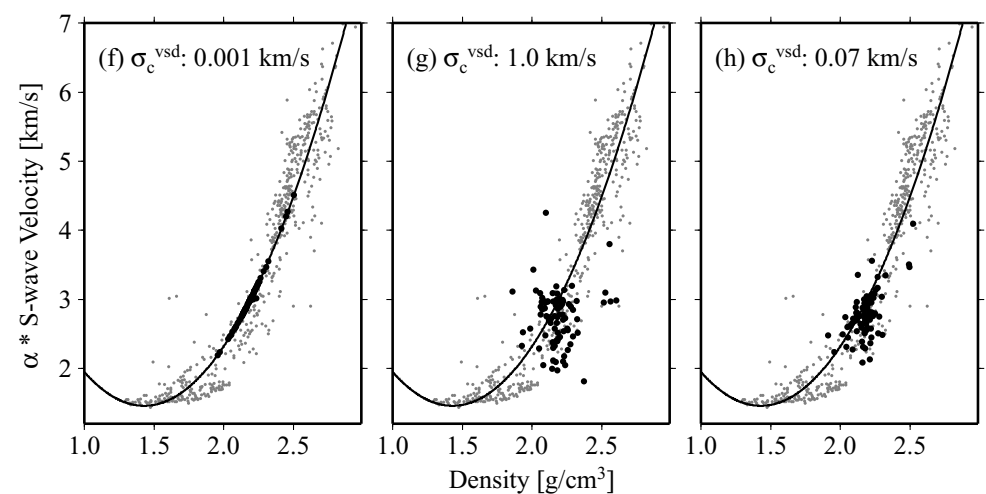

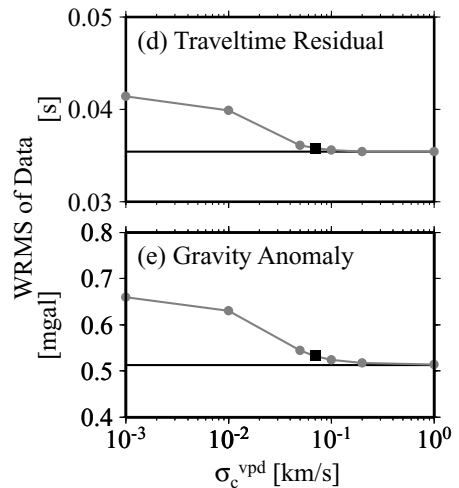

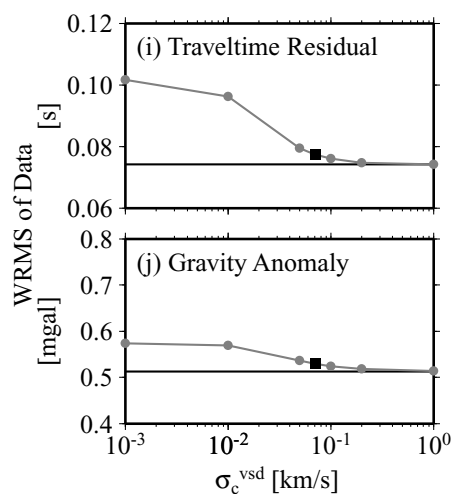

Fig. 7. (a)-(c), (f)-(h) Velocities and density after the test inversion for selecting $\sigma_{c} \mathrm{~s}$. (a) and (f) for strong constraint case. (b) and (g) for weak constraint case. (c) and (h) for the case of parameter adopted for the inversion. Solid curve: the constraint curve used for the inversion. Gray dots: the samples by Nafe and Drake (1963). Solid circles: velocity and density values obtained after the test inversion. For the S-wave velocity-density constraint, $\alpha$ was multiplied with S-wave velocity to compare the samples. (d), (e), (i), (j) WRMS of traveltime residuals and gravity anomalies versus $\sigma_{c}$. Solid horizontal lines: WRMS for the non-constrained case. Solid squares: parameters selected for the inversion.

Table 1. Target function, WRMS of data before and after the simultaneous inversion.

\begin{tabular}{c|cccc} 
& Target Function & WRMS \\
& & P-wave [s] & S-wave [s] & Grav. [mgal] \\
Initial & $2.839 \times 10^{5}$ & 0.065 & 0.171 & 1.022 \\
Final & $7.341 \times 10^{4}$ & 0.031 & 0.068 & 0.550 \\
(Reduction) & $(74 \%)$ & $(52 \%)$ & $(60 \%)$ & $(46 \%)$
\end{tabular}

$1.25 \mathrm{~km}$, a high velocity belt striking in the NW-SE direction is detected. A high velocity anomaly beneath the caldera is observed at a depth of $2.5 \mathrm{~km}$. At depths of $4 \mathrm{~km}$ and deeper, the reconstruction of the synthetic velocity structure in the checkerboard test is poor.

The synthetic S-wave model (Figs. 9(i)-(1)) is well reconstructed at $0.25 \mathrm{~km}$ depth, where the gravity constraint is imposed. The pattern is still well reconstructed at $1.25 \mathrm{~km}$, although slightly poorer than that constructed from the P-wave synthetics. At these depths, the velocity pattern is similar to the P-wave velocity model (Figs. 9(a) and (b)). At $0.25 \mathrm{~km}$ a high velocity region well correlated with the caldera rim is observed and coincides with the P-wave velocity model.

Little change in hypocenter locations was observed after the inversion, while hypocenters obtained after the station corrections were applied exhibited significant differences from the initial hypocenters. This implies that shal- low three-dimensional heterogeneity significantly affects the hypocenter locations.

The density anomaly obtained in this inversion is shown in Fig. 10(a). The general pattern was anticipated from the observed gravity anomaly data (Fig. 5). The most prominent feature, the high density anomaly inside the caldera, was observed as expected. As seen in Table 1, the calculated gravity anomaly (Fig. 10(b)) agrees well with the observed anomaly.

\section{Discussion}

\subsection{Inversion method}

In order to observe the effect of additional gravity data on the first layer, $0.25 \mathrm{~km}$ as a constraint in the simultaneous inversion, a velocity inversion using only traveltime residual data was performed. The traveltime data, grid configuration and other parameters were the same as those used in the simultaneous inversion. A checkerboard test corresponding to the velocity inversion was also carried out. The results of the inversion are shown in Figs. 11 and 12 for P- and S-wave velocities, respectively. The P-wave velocity structure is very similar to the result of the simultaneous inversion (Fig. 8). Although the checkerboard pattern reconstructed by the velocity inversion is a little bit poorer than that reconstructed by the simultaneous inversion, the synthetic checkerboard patterns are well reconstructed to a depth of $2.5 \mathrm{~km}$. At a depth 

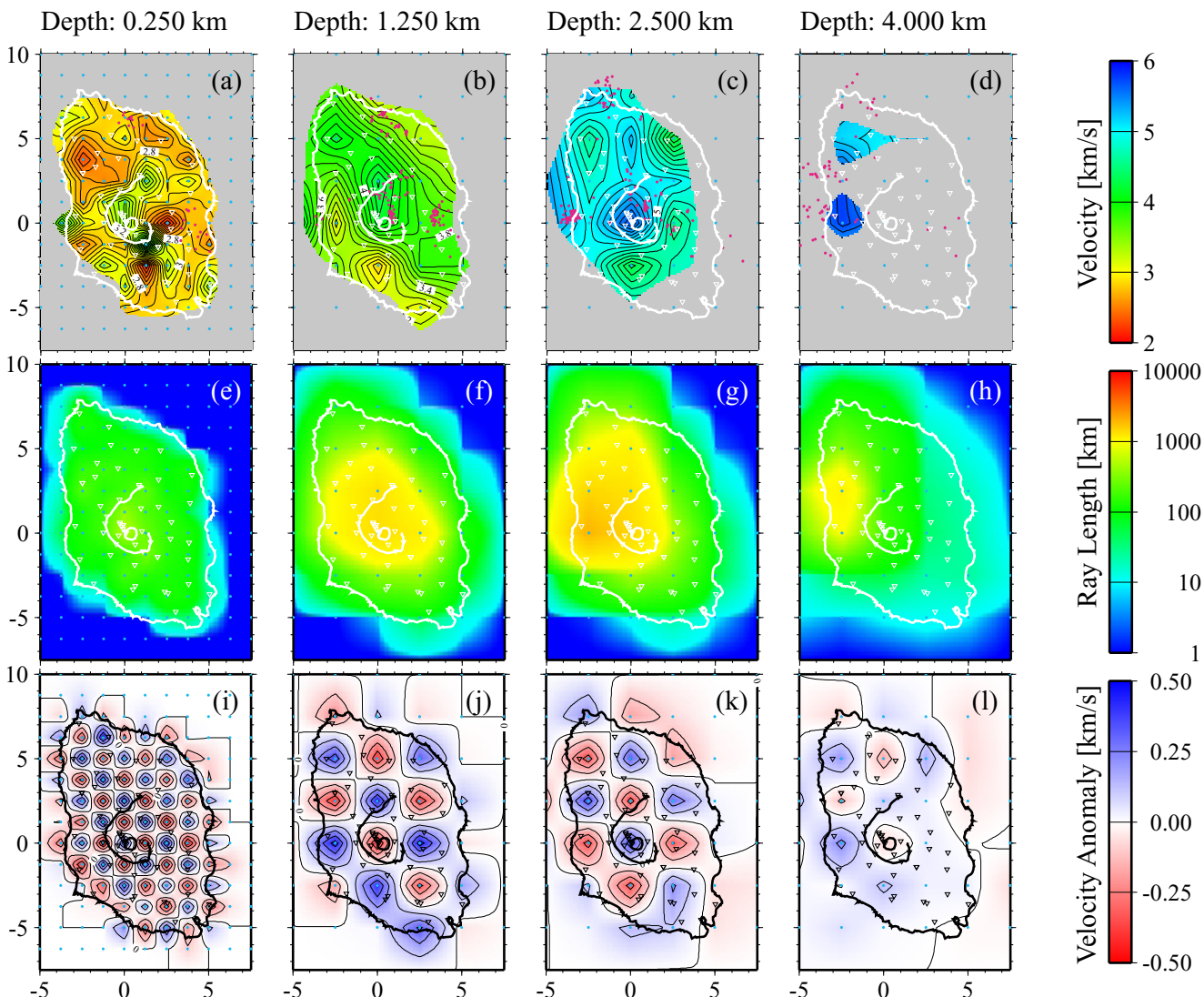

Fig. 8. P-wave velocity after the simultaneous inversion using traveltime and gravity data. Light blue dots show locations of grid points. (a)-(d): resultant P-wave velocity structure. Purple dots are final hypocenters. (e)-(h): total ray length contributed for determining velocity at each grid. (i)-(l): result of corresponding checkerboard test.
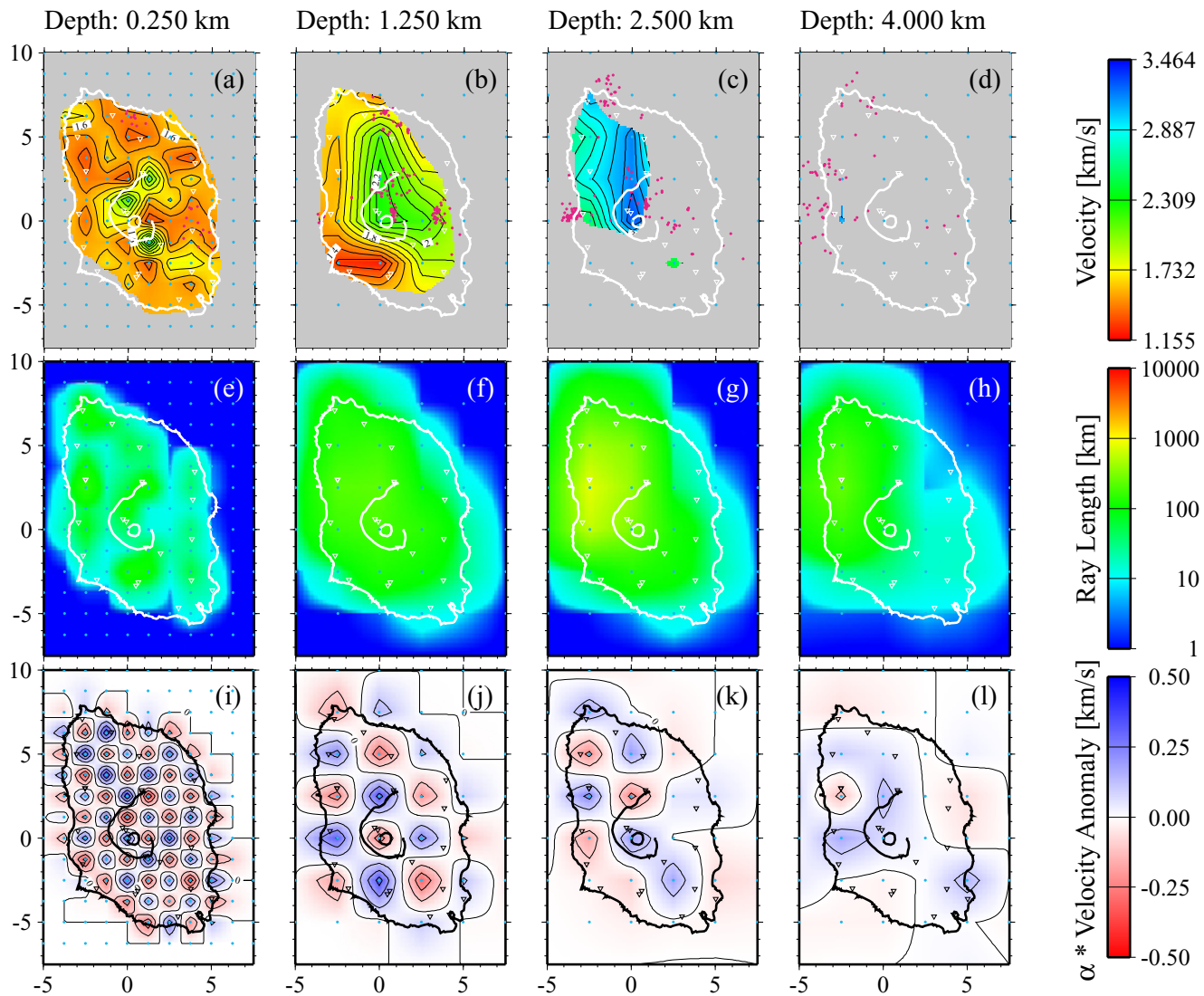

Fig. 9. S-wave velocity after the simultaneous inversion using traveltime and gravity data. Light blue dots show locations of grid points. (a)-(d): resultant S-wave velocity structure. Purple dots are final hypocenters. (e)-(h): total ray length contributed for determining velocity at each grid. (i)-(l): result of corresponding checkerboard test. $\alpha$ s were multiplied with S-wave velocity anomaly. 
(a)

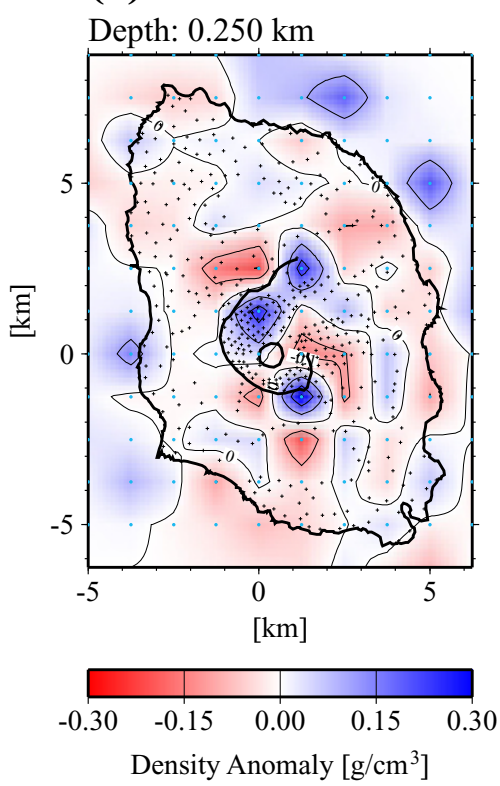

(b)

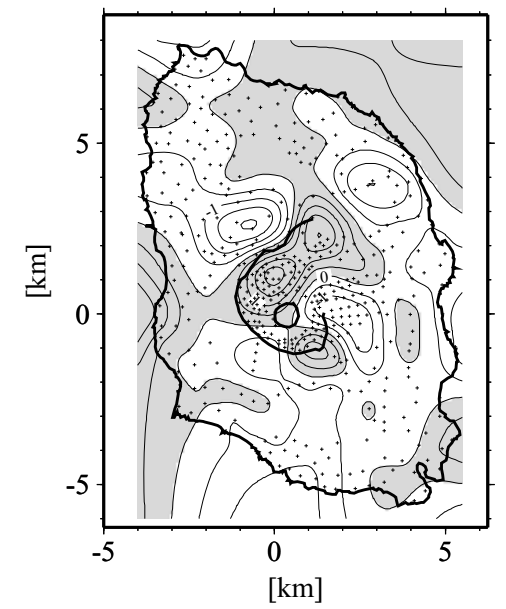

Fig. 10. (a) Density anomaly after the simultaneous inversion. (b) Calculated gravity anomaly. Contour interval is 0.5 mgal. Shaded and white areas correspond to positive and negative anomalies, respectively.

of $0.25 \mathrm{~km}$, the pattern is almost completely reconstructed in the central part of the model. These results indicate that for P-waves, traveltime data alone are sufficient to determine the velocity structure in this grid configuration even at the first layer. Therefore, for the P-wave model, additional gravity data are not necessary and the increase in the amount of traveltime data results in an improved spatial resolution of the velocity structure compared to previous studies.

The synthetic S-wave checkerboard pattern was not well reconstructed at the first layer by the velocity inversion (Fig. 12), while in the simultaneous inversion the synthetic structure was reconstructed better (Fig. 9). This may indicate that the improvement in the simultaneous inversion was due to additional gravity data. However, the improvement could also be due to the contribution of P-wave traveltime data, because, in the test inversion, the synthetic S-wave velocity is consistent with not only density, but also P-wave velocity through the constraint relationships, and P-wave velocity had sufficient resolution. Thus, we performed the checkerboard test for S-wave velocity and density without P-wave traveltime data in order to assess the effect by gravity data only. As a result, reconstructions very similar to those in Figs. 9(i)-(1) were obtained. Therefore we can conclude that the improvement of S-wave velocity resolution is not due to the inclusion of $\mathrm{P}$-wave traveltime data. This indicates that gravity data can improve the S-wave velocity structure at the first layer where the constraint was imposed.

The area of Izu-Oshima island is about $90 \mathrm{~km}^{2}$, and the numbers of seismic stations used for this study were 56 for $\mathrm{P}$-waves and 24 for S-waves. Average station intervals are about $1.3 \mathrm{~km}$ and $1.9 \mathrm{~km}$, respectively. The station interval for P-waves is similar to the horizontal grid interval of the first layer, while for S-waves the station interval is longer. This may be a reason for the difference in the contribution of gravity data to the derived velocity structure. We also performed test inversions for P-waves which simulate sparse seismic stations and found that the results were also improved by introducing additional gravity data.

The relationship between velocity and density, and the deviation from this relationship, are essential to this method. If the assumed relation differs from the real, incorrect results may be introduced, and improvement of the velocity structure by the introduction of additional gravity data is not guaranteed. The deviation from the relationship is also important, as it contributes to the determination of relative weights for constraints in the inversion. In this study, for P-wave velocity and density constraints, we used an empirical curve that fits data of marine sediments and sedimentary rocks (Nafe and Drake, 1963). The relationship between S-wave velocity and density was also based on this empirical curve. We selected the $\sigma_{c}$ s so that the deviation after inversion was similar to that of the rock samples used to define the curve. Currently, we do not know whether our adopted relationship and its deviation are the best choice for application to Izu-Oshima volcano. At Izu-Oshima volcano, core samples were obtained from a borehole drilled in the caldera. However, the physical properties of the samples such as seismic velocities and densities have not yet been measured. In order to improve the results further, velocity - density relationships that are appropriate for the locality need to be defined. We also need to improve the theoretical framework so that it can represent not only the local relationships, but also the deviation from these relationships at the scales of inversion resolution. We will then be able to apply our method more generally.

\subsection{Subsurface structure of Izu-Oshima volcano}

In order to improve the spatial resolution of the shallow velocity structure over previous studies, the simultaneous inversion was performed with additional gravity data and the amount of traveltime data was greatly increased in this study. As a result, velocity structures with higher spatial resolution 

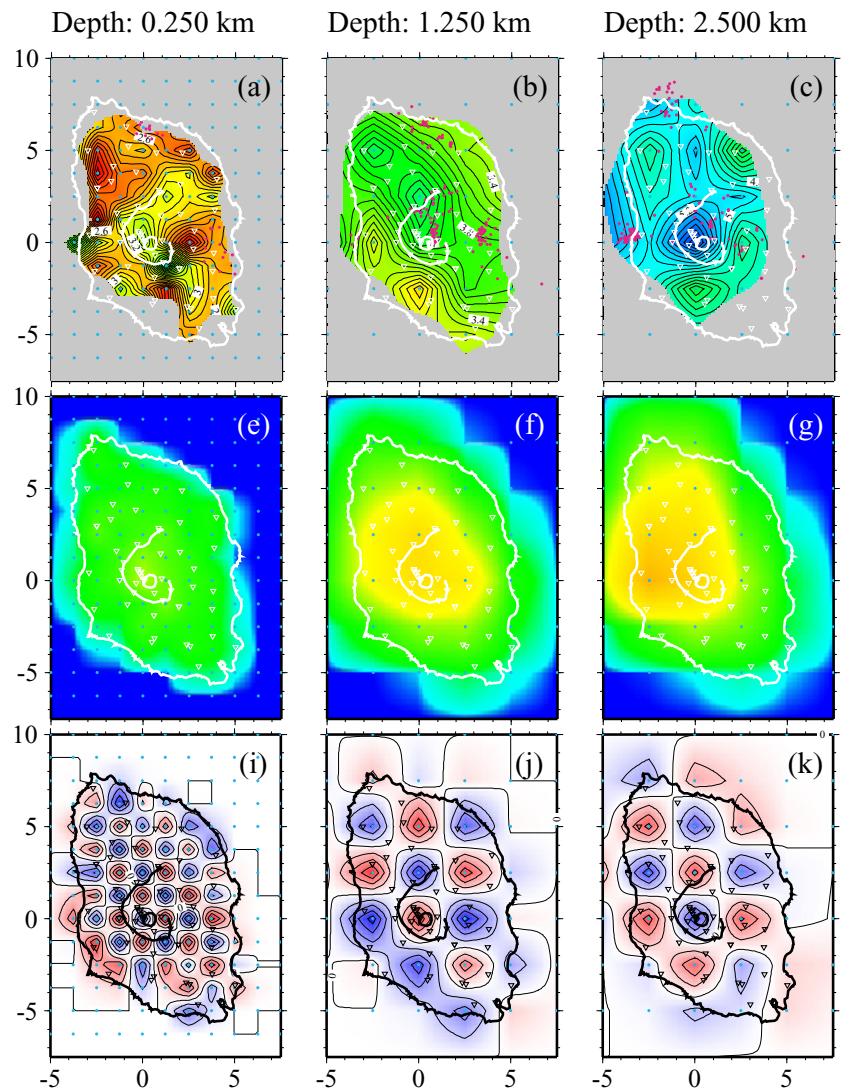

Depth: $4.000 \mathrm{~km}$
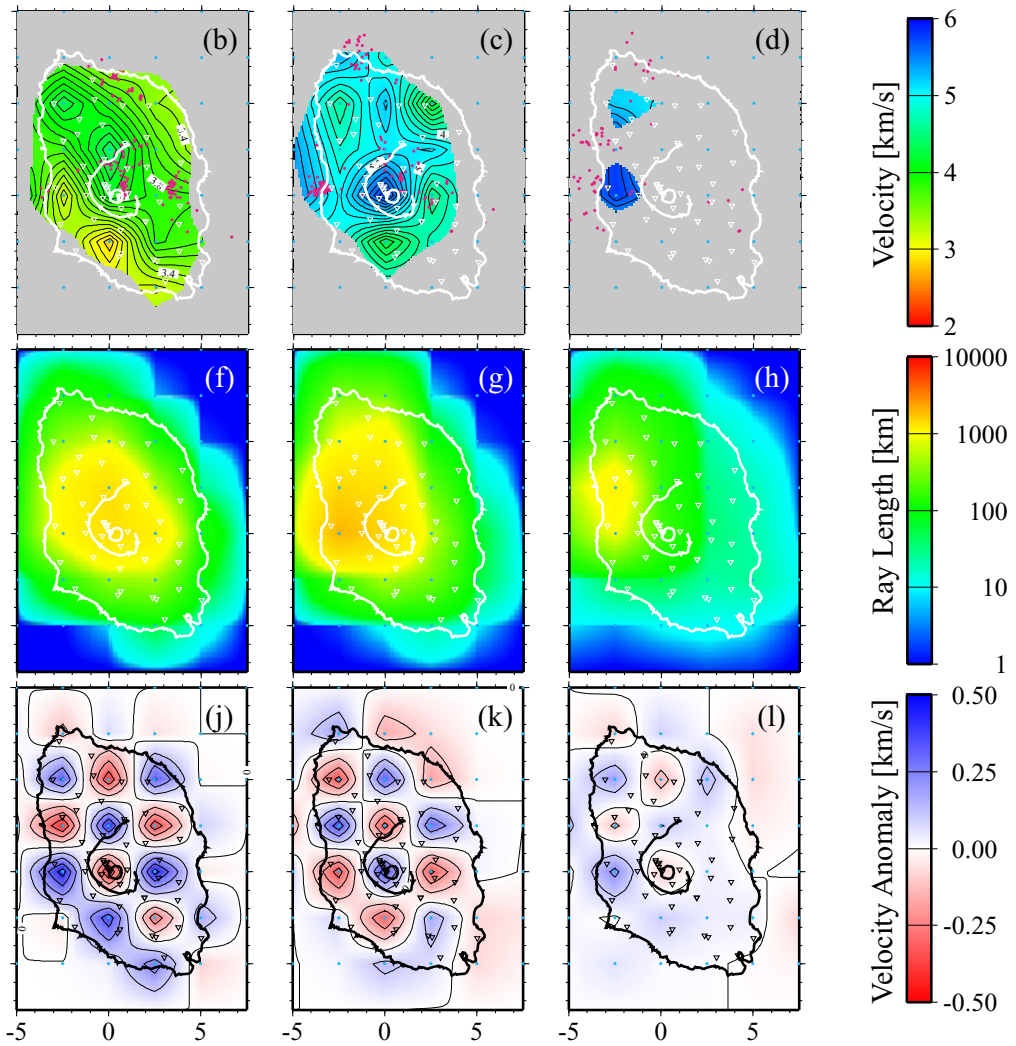

Fig. 11. P-wave velocity after the velocity inversion using traveltime data only. Notation is the same as Fig. 8 . The results are similar to those shown in Fig. 8.

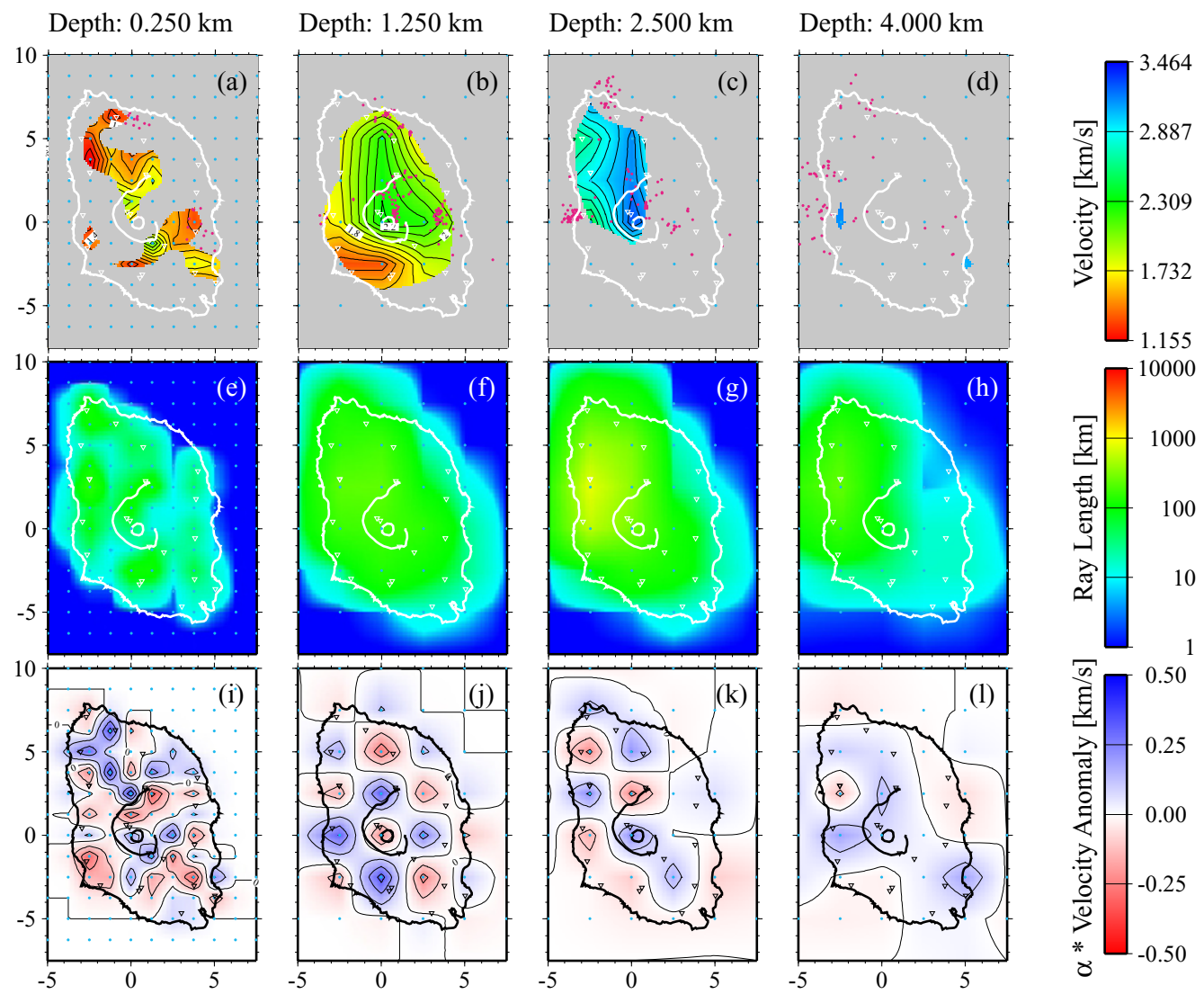

Fig. 12. S-wave velocity after the velocity inversion using traveltime data only. Notation is the same as Fig. 9 . At the depth of 0.25 km, the checkerboard test result is much worse compared to that shown in Fig. 9. 
were obtained. The most impressive improvements are observed at depths of 0.25 and $1.25 \mathrm{~km}$, where only a high velocity anomaly beneath the caldera had been detected in previous studies.

At the depth of $0.25 \mathrm{~km}$, a high velocity area enclosed by the caldera rim was detected for P- and S-waves. This correlates well with the topography. This result was expected, since Ando et al. (1994) had already observed a high gravity anomaly inside the caldera rim (Fig. 5). This anomaly was interpreted as due to the accumulation of dense lava flows filling the caldera floor. In our analysis, this feature was also detected as a high velocity region.

A high $\mathrm{P}$-wave velocity belt striking NW-SE direction at $1.25 \mathrm{~km}$ depth is newly discovered by the study. The high velocity region coincides with the extent of an intensely magnetized body inferred from aeromagnetic data by Makino et al. (1988) (Fig. 13). This anomaly can be interpreted as due to the repeated intrusion of dikes because flank volcanoes, dikes and eruptive fissures are aligned in the NW-SE direction (Nakamura, 1964), which, in this region, is also the axis of maximum compressional stress into which magma is apt to intrude (Nakamura, 1977). Indeed, at the time of the fissure eruption in 1986, the eruptive vents trended in the NWSE direction. Furthermore, after the beginning of the fissure eruption, hypocenters migrated to the SE and NW from the fissure vents (Yamaoka et al., 1988). From geodetic data, Hashimoto and Tada (1988) inferred that a NW-SE elongated tensile crack opened during the eruption. At a depth of $2.5 \mathrm{~km}$, the NW-SE trending high velocity anomaly is

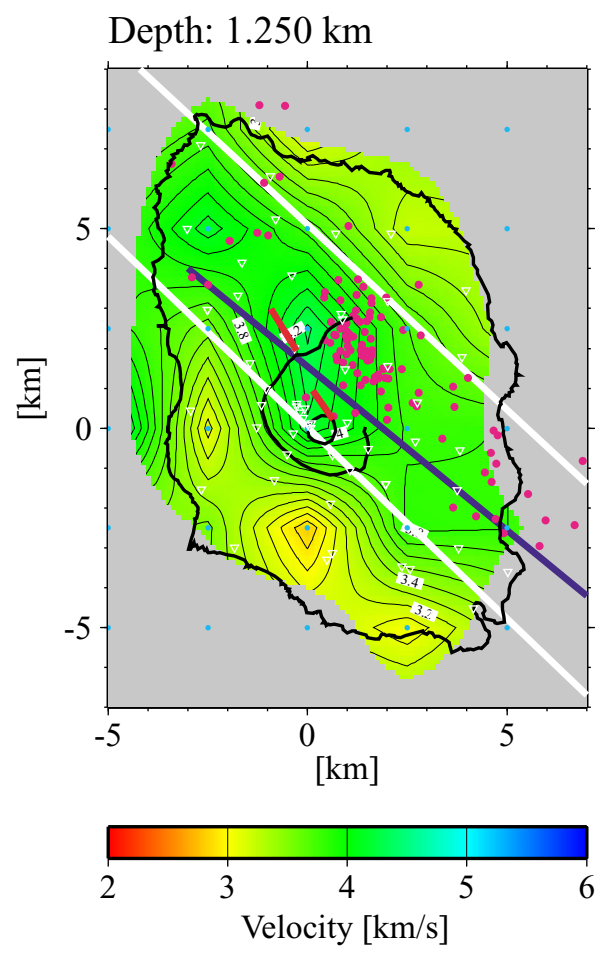

Fig. 13. P-wave velocity at depth of $1.25 \mathrm{~km}$. Area sandwiched by white lines: intensely magnetized body (Makino et al., 1988). Purple dots: hypocenter locations of earthquakes after the fissure eruption in 1986 (Yamaoka et al., 1988). Blue line: tensile crack accompanying the eruption (Hashimoto and Tada, 1988). Red lines: the 1986 eruptive fissures. not detected and this is perhaps due to a lower velocity contrast between dikes and host rocks. Some dikes might have continued deeper than $2.5 \mathrm{~km}$ because earthquake hypocenters following the fissure eruption and the tensile crack inferred from the geodetic data extended to greater depths. At the depth of $2.5 \mathrm{~km}$, a high velocity beneath the caldera was observed. In Izu-Oshima volcano, magmas have mainly erupted from the summit rather than from flank fissures, at least since the formation of the caldera about 1500 years ago, though fissure eruptions also occurred in 1986. The high velocity beneath the caldera may be caused by intrusive bodies related to a magmatic pathway to the summit. High velocity bodies due to intruded magma have been detected along magma transport regions beneath the summit and rift zones of Hawaiian volcanoes (Okubo et al., 1997). Such intrusive bodies, which indicate magmatic pathways, were also detected at Izu-Oshima volcano by this study. Such prominent high velocities imply a higher proportion of intrusive rocks in these regions and that a substantial amount of magma has been emplaced under the volcano without extrusion.

The detection of a magma chamber is one of the most important targets of investigations of the subsurface structure beneath volcanoes. In Izu-Oshima volcano, magma chambers have been inferred at depths of 4-5 km and 8-10 km by several researchers (e.g., Aramaki and Fujii, 1988; Ida, 1995; Ida et al., 1988; Watanabe, 1990; Watanabe, 1998; Mikada et al., 1997). In this study, however, velocity anomalies coinciding with these magma chambers could not be detected because few seismic rays penetrate to these depths. The target region of the inversion depends on the extent of the seismogenic zone when we investigate velocity structure using local earthquake data. In volcanic regions, the lower limit of the seismogenic zone tends to become shallower compared to surrounding areas because of the relatively high temperature of magmatic bodies (Ito, 1993). This feature can be seen in Izu-Oshima volcano (Fig. 4(d)) and prohibits our investigating deeper regions. For models deeper than $4 \mathrm{~km}$, which are needed to clarify the magma plumbing system, use of teleseismic or regional earthquake data is required.

\section{Conclusions}

We formulated a method for three-dimensional simultaneous velocity and density inversion using local earthquake traveltime and gravity data. The gravity data contribute to $\mathrm{P}$ - and S-wave velocity models by imposing constraints between velocities and density. For the constraints, a non-linear curve derived so as to fit the samples of porous sediments and sedimentary rocks was used. In the formulation, deviations from the constraint curve were permitted. From the results of test inversions using synthetic data, we showed that gravity data improves the results of the velocity inversions at the first layer where the constraint was imposed.

The inversion method was applied with traveltime and gravity data to investigate the subsurface structure of IzuOshima volcano. As a result, velocity structures at higher spatial resolution compared to previous studies were obtained to a depth of $2.5 \mathrm{~km}$. The gravity data contributed especially to the S-wave velocity structure at the first layer. The characteristics of the revealed features are summarized as follows: (1) a high velocity area enclosed by the caldera 
rim at a depth of $0.25 \mathrm{~km}$ is observed, which is probably due to dense lava flows filling the caldera floor and (2) high velocity intrusive bodies are detected at depths of 1.25 and 2.5 $\mathrm{km}$. The high velocity anomaly at a depth of $1.25 \mathrm{~km}$ strikes in the NW-SE direction and is interpreted as due to repeated intrusion of dikes.

Acknowledgments. We are grateful to S. Okubo, T. Iwasaki and $\mathrm{K}$. Koketsu for their helpful comments during development of this method. We are indebted to T. Kagiyama for his repeated encouragement and constructive advice for our study. Helpful and critical comments by two reviewers, T. Ohminato and P. Dawson, greatly improved our manuscript. English usage in the manuscript was improved by T. Wright. We would also like to thank J. Ando, whose vigorous field work enabled us to carry out this study. For this study, we used the computer systems of Earthquake Information Center of Earthquake Research Institute, University of Tokyo.

\section{References}

Ando, J., H. Watanabe, and S. Sakashita, Study of gravity anomaly on and around Izu-Oshima volcano, Bull. Earthq. Res. Inst., Univ. Tokyo, 69, 309-350, 1994 (in Japanese with English abstract).

Aramaki, S. and T. Fujii, Petrological and geological model of the 19861987 eruption of Izu-Oshima volcano, Bull. Volcanol. Soc. Japan, 33 S297-S306, 1988 (in Japanese with English abstract).

Birch, F., The velocity of compressional waves in rocks to 10 kilobars, part 2, J. Geophys. Res., 66, 2199-2224, 1961.

Gardner, G. H. F., L. W. Gardner, and A. R. Gregory, Formation velocity and density-The diagnostic basics for stratigraphic traps, Geophysics, 39, 770-780, 1974.

Hasegawa, I., K. Ito, K. Ono, T. Aihara, K. Kusunose, and T. Satoh, Crustal structure of Izu-Oshima island revealed by explosion seismic measurements-A profile across the island, Bull. Geol. Surv. Japan, 38, 741-753, 1987 (in Japanese with English abstract).

Hashimoto, M. and T. Tada, Crustal deformations before and after the 1986 eruption of Izu-Oshima volcano, Bull. Volcanol. Soc. Japan, 33, S136S144, 1988 (in Japanese with English abstract).

Ida, Y., Magma chamber and eruptive processes at Izu-Oshima volcano, Japan: buoyancy control of magma migration, J. Volcanol. Geotherm. Res., 66, 53-67, 1995.

Ida, Y., K. Yamaoka, and H. Watanabe, Underground magmatic activities associated with the 1986 eruption of Izu-Oshima volcano, Bull. Volcanol. Soc. Japan, 33, S307-S318, 1988 (in Japanese with English abstract).

Ito, K., Cutoff depth of seismicity and large earthquakes near active volcanoes in Japan, Tectonophys., 217, 11-21, 1993.

Jackson, D. D. and M. Matsu'ura, A Bayesian approach to nonlinear inversion, J. Geophys. Res., 90, 581-591, 1985.

Kato, S. and Seabottom Survey Group around O-Sima Volcano after 1986 Eruption, Seabottom survey around O-sima island of Izu-Ogasawara arc, Report of Hydrographic Researches, 23, 177-185, 1987 (in Japanese with English abstract).

Lee, W. H. K. and S. W. Stewart, Principles and applications of microearthquake networks, Adv. Geophys. Suppl. 2, 293 pp., 1981

Lees, J. M. and J. C. VanDecar, Seismic tomography constrained by Bouguer gravity anomalies: Applications in Western Washington, $P A$ $G E O P H, 135,31-52,1991$.

Ludwig, W. J., J. E. Nafe, and C. L. Drake, Seismic refraction, in The Sea, Vol. 4, edited by A. E. Maxwell, pp. 53-84, Wiley Interscience, New York, 1970.

Makino, M., T. Nakatsuka, S. Okuma, and T. Kaneko, Aeromagnetic anomalies over the Izu-Oshima volcano, Bull. Volcanol. Soc. Japan, $\mathbf{3 3}$ S217-S223, 1988 (in Japanese with English abstract).
Mikada, H., An Elastic Scattering Theory and Its Application to the Understanding of Subsurface Structure of Izu-Oshima Volcano, PhD thesis, University of Tokyo, 159 pp., 1994.

Mikada, H., H. Watanabe, and S. Sakashita, Evidence for subsurface magma bodies beneath Izu-Oshima volcano inferred from a seismic scattering analysis and possible interpretation of the magma plumbing system of 1986 eruptive activity, Phys. Earth Planet. Int., 104, 257-269, 1997.

Nafe, J. E. and C. L. Drake, Physical properties of marine sediments, in The Sea, Vol. 3, edited by M. N. Hill, pp. 794-815, Interscience, New York, 1963.

Nagy, D., The gravitational attraction of a right rectangular prism, Geophysics, 31, 362-371, 1966.

Nakamura, K., Volcano-stratigraphic study of Oshima volcano, Izu, Bull. Earthq. Res. Inst., Univ. Tokyo, 42, 649-728, 1964.

Nakamura, K., Volcanoes as possible indicators of tectonic stress orientation-Principle and proposal, J. Volcanol. Geotherm. Res., 2, 1 16, 1977.

Nakamura, K., K. Shimazaki, and N. Yonekura, Subduction, bending and eduction. Present and Quaternary tectonics of the northern border of the Philippine Sea plate, Bull. Soc. Feol. France, 26, 221-243, 1984.

Okubo, P. G., H. M. Benz, and B. A. Chouet, Imaging the crustal magma sources beneath Mauna Loa and Kilauea volcanoes, Hawaii, Geology, 25, 867-870, 1997.

Sakashita, S., T. Shimomura, H. Mikada, and H. Watanabe, Volcano monitoring at Izu-Oshima Volcano Observatory, Earthquake Research Institute, University of Tokyo, Tech. Res. Rep., Earthq. Res. Inst., Univ. of Tokyo, 7-17, 1996 (in Japanese with English abstract).

Scales, J. A., Tomographic inversion via the conjugate gradient method, Geophysics, 52, 179-185, 1987.

Suyehiro, K., N. Takahashi, Y. Ariie, Y. Yokoi, R. Hino, M. Shinohara, T. Kanazawa, N. Hirata, H. Tokuyama, and A. Taira, Continental crust, crustal underplating, and low-Q upper mantle beneath an oceanic island arc, Science, 272, 390-392, 1996.

Talwani, M., Computer usage in the computation of gravity anomalies, in Method in Computational Physics: Advances in Research and Applications; Vol. 13, edited by B. A. Bolt, 473 pp., Academic Press, New York, 1973.

Thurber, C. H., Earthquake locations and three-dimensional crustal structure in the Coyote Lake Area, Central California, J. Geophys. Res., 88, 8226$8236,1983$.

Um, J. and C. Thurber, A fast algorithm for two-point seismic ray tracing, Bull. Seismol. Soc. Am., 77, 972-986, 1987.

Watanabe, H., Precursors to eruption and volcano prediction, Bull. Volcanol. Soc. Japan, 34, S215-S226, 1990 (in Japanese).

Watanabe, H., Precursors to the 1986 eruption and the magma plumbing system of Izu-Oshima volcano, Bull. Volcanol. Soc. Japan, 43, 271-282, 1998 (in Japanese with English abstract).

Watanabe, H., Borehole density data in the caldera of Izu-Oshima volcano, unpublished.

Yakiwara, H. and H. Shimizu, Three dimensional velocity structure of crust and upper mantle under the volcanoes, Kyushu, Prog. Abst. Volcanol. Soc. Japan, 1997 (in Japanese).

Yamamoto, K., Three-Dimensional P-wave Velocity Structure of IzuOshima Volcano, Japan by Using Teleseismic Data: for Detection of Magma Reservoir, Master's thesis, University of Tokyo, 52 pp., 1993.

Yamaoka, K., H. Watanabe, and S. Sakashita, Seismicity during the 1986 eruption of Izu-Oshima volcano, Bull. Volcanol. Soc. Japan, 33, S91S101, 1988 (in Japanese with English abstract).

S. Onizawa (e-mail: onizawa@eos.hokudai.ac.jp), H. Mikada (email: mikada@jamstec.go.jp), H. Watanabe (e-mail: watanabe@eri.utokyo.ac.jp), and S. Sakashita 